UNIVERSIDADE DE BRASÍLIA

FACULDADE DE CIÊNCIAS DA SAÚDE

PROGRAMA DE PÓS-GRADUAÇÃO EM SAÚDE COLETIVA

DANIELA CRISTINA MOREIRA MARCULINO DE FIGUEIREDO

ATENÇÃO BÁSICA: ANÁLISE DA UTILIŻAÇÃO PELOS USUÁRIOS DO SISTEMA ÚNICO DE SAÚDE NO BRASIL 


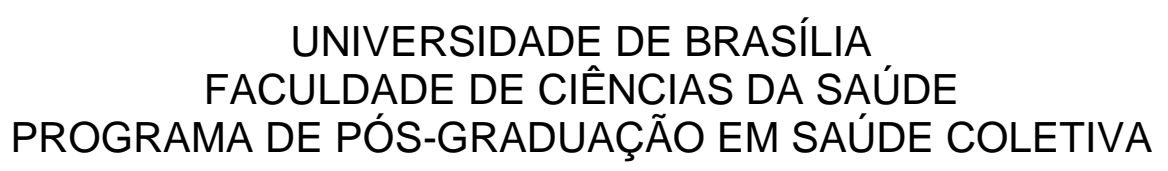

DANIELA CRISTINA MOREIRA MARCULINO DE FIGUEIREDO

\section{ATENÇÃO BÁSICA: ANÁLISE DA UTILIZAÇÃO PELOS USUÁRIOS DO SISTEMA ÚNICO DE SAÚDE NO BRASIL}

Dissertação apresentada ao Programa de PósGraduação em Saúde Coletiva, como requisito para a obtenção do título de Mestre em Saúde Coletiva - Mestrado Profissional, na linha de pesquisa de Políticas, Planejamento, Gestão e Atenção em Saúde.

Orientadora: Prof ${ }^{a}$. Dr a . Helena Eri Shimizu

Coorientador: Walter Massa Ramalho 
DANIELA CRISTINA MOREIRA MARCULINO DE FIGUEIREDO

ATENÇÃO BÁSICA: ANÁLISE DA UTILIZAÇÃO PELOS USUÁRIOS DO SISTEMA ÚNICO DE SAUUDE NO BRASIL.

Dissertação apresentada ao Programa de PósGraduação em Saúde Coletiva, como requisito para a obtenção do título de Mestre em Saúde Coletiva - Mestrado Profissional, na linha de pesquisa de Políticas, Planejamento, Gestão e Atenção em Saúde.

\section{BANCA EXAMINADORA}

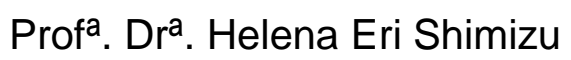

Presidente

Prof $\stackrel{a}{\text {. Drạ. }}$. Kerle Dayana Tavares de Lucena

Examinadora

Prof ${ }^{a}$. Dra ${ }^{\mathrm{a}}$. Maria Cristina Soares Rodrigues

Examinadora

Prof ${ }^{\mathrm{a}}$. Dra . Tania Cristina Morais Santa Bárbara Rehem

Examinadora Suplente 
"Alô, liberdade Desculpa eu vir Assim sem avisar Mas já era tarde E os galos tão Cansados de cantar Bom dia, alegria A minha companhia Vai cantar Sutil melodia Pra te acordar Alô liberdade Levante, lava o rosto Fica em pé".

(Chico Buarque) 


\section{AGRADECIMENTOS}

Agradeço a todas as pessoas que, de alguma forma, me ajudaram a realizar esse trabalho e que me apoiaram nesta conquista:

Aos meus queridos pais que com tanto esforço, carinho e apoio me conduziram à formação da pessoa que me tornei. Uma pessoa que acredita, persiste e insiste ser possível um mundo mais justo e fraterno. Obrigada por compartilharem comigo cada vitória e me amparar nas minhas dificuldades. Essa conquista é nossa!

Ao meu companheiro, Alexandre Medeiros de Figueiredo, por sonhar comigo sempre, me apoiar nas minhas lutas e me inspirar. Por se fazer presente em nosso lar, junto às nossas pequenas, quando, por vezes, precisei me ausentar.

Às minhas filhas, meu tudo, minha vida. Só posso agradecer por tê-las comigo. Pela honra de ser mãe e de conduzi-las na jornada da vida. Pela doçura, pureza e tantos aprendizados. Por me tornarem uma pessoa melhor, fazendo os meus dias tão mais vivos, perfumados e felizes.

À minha orientadora, Helena Eri Shimizu, por compartilhar comigo de sua experiência e saberes e por me apoiar neste trabalho, construindo novos conhecimentos e afetos.

Ao meu coorientador, Walter Massa Ramalho, pelo apoio, conhecimentos compartilhados, humor e carinho me auxiliando na construção deste trabalho.

Aos amigos Luciano Bezerra e Kerle Lucena que me incentivaram, desde o início.

Aos meus queridos colegas do Programa de Pós-Graduação em Saúde Coletiva pelas parcerias e por tornarem mais leve esse período, compartilhando as alegrias e conquistas.

Aos companheiros do Departamento de Atenção Básica do Ministério da Saúde, onde pude vivenciar o dia a dia da gestão federal do SUS e do apoio institucional, mas também onde foi possível produzir laços de afetos, sonhos, luta e amizade. 


\section{RESUMO}

A análise dos serviços de saúde quanto a sua utilização é um importante indicador a ser considerado no planejamento das ações. E após grandes esforços em ampliar a cobertura da Atenção Primária no Brasil, faz-se necessária a análise e avaliação do acesso e da qualidade dos serviços de saúde, sendo a população um importante ator analítico desse processo. O presente estudo descreve os resultados da avaliação dos usuários participantes do Programa de Melhoria do Acesso e da Qualidade na Atenção Básica (PMAQ-AB) em relação aos atributos essenciais da Atenção Primária à Saúde (Acesso, Integralidade, Longitudinalidade e Coordenação do Cuidado). Trata-se de um estudo descritivo, de abordagem quantitativa, baseado em dados secundários selecionados e gerados a partir do banco de dados, de base nacional e domínio público, da avaliação externa, realizada em 2012, do primeiro ciclo do PMAQ-AB. O estudo apresentou como amostra os 65.391 usuários participantes do primeiro ciclo do Programa. Os dados revelaram distâncias geográficas como barreiras importantes, sobretudo na região Norte do país, assim como a ausência do profissional médico em todos os turnos e a impossibilidade na escolha dos profissionais. Embora existam estratégias e instrumentos que induzem - acesso aos serviços, ainda são evidentes as barreiras de acessibilidade organizacional, em que 0 acesso à unidade se dá a partir de fichas e filas e a população não reconhece a Atenção Primária como espaço para os atendimentos de urgência. $O$ estudo revelou ainda a necessidade de incorporar na prática dos profissionais de saúde a percepção sobre as questões que vão além do motivo que leva o usuário a buscar o serviço de saúde, bem como na oferta de cuidados compatíveis com a realidade dos mesmos, de modo a produzir projetos terapêuticos eficientes, aplicáveis e efetivos. É necessário, também, minimizar a rotatividade dos profissionais, através de políticas que intervenham na problemática da precarização do trabalho, uma vez que o vínculo e a continuidade do cuidado são fundamentais para a qualidade, bem como contribuem para a valorização perante a sociedade da Atenção Primária no Brasil como produtora de cuidado. Nesse sentido, espera-se que o estudo seja elemento de orientação na gestão pública revelando as necessidades apontadas pelos usuários, quanto à melhoria do acesso e da qualidade, no sentido de direcionar a formulação das políticas, ações e estratégias, no campo da atenção, formação e organização do sistema de saúde, voltadas para as questões que ainda são consideradas desafios para uma Atenção Primária acessível, resolutiva e cuidadora.

Palavras-chave: Atenção Primária à Saúde; Avaliação em saúde; Qualidade, Acesso e Avaliação da Assistência à Saúde; Integralidade em saúde. 


\begin{abstract}
The analysis of health services as their use is an important indicator to be considered in the planning of actions. And after great efforts in expanding the coverage of primary health care in Brazil, it is necessary to analysis and evaluation of access and quality of health services, and the population an important analytical stage of the process. This study describes the results of the evaluation of the participating users of Access Improvement Programme and Quality in Primary Care (PMAQ -AB) on the essential attributes of primary health care (access, integrality, longitudinality and coordination of care). This is a descriptive study with a quantitative approach, based on selected secondary data and generated from the database of national and public domain base, the external evaluation in 2012, the first PMAQ-AB cycle. The study presented as a sample the 65,391 users participating in the first program cycle. The data revealed geographical distances as significant obstacles, especially in the north of the country, as well as the absence of medical professional on all shifts and the impossibility in the choice of professionals. Although there are strategies and tools that induce access to services, it is still evident the organizational accessibility barriers in the access unit occurs from chips and queues and the population does not recognize the Primary as space for emergency care. The study also revealed the need to incorporate the practice of health professional perception on issues that go beyond the reason that takes the user to seek the health service, as well as in the provision of care consistent with the reality of them, so to produce efficient therapeutic projects, applicable and effective. It is also necessary to minimize the turnover of professionals, through policies that intervene in the issue of precarious work, since the bond and continuity of care are fundamental to the quality and contribute to the value to society of Attention Primary in Brazil as a producer of care. In this sense, it is expected that the study is guiding element in public management revealing the needs identified by users as to improve access and quality in order to direct the formulation of policies, actions and strategies in the field of attention, training and organization of the health system, focused on the issues that are still considered challenges for Primary accessible, solving and caring.
\end{abstract}

Key words: Primary Health Care; Health evaluation; Health care quality, access, and evaluation; Integrality in health. 


\section{LISTA DE ABREVIATURAS E SIGLAS}

$\begin{array}{ll}\text { AB } & \text { Atenção Básica } \\ \text { ABS } & \text { Atenção Básica à Saúde } \\ \text { AE } & \text { Avaliação Externa } \\ \text { APS } & \text { Atenção Primária à Saúde } \\ \text { COAP } & \text { Contrato Organizativo de Ação Pública } \\ \text { CnaR } & \text { Consultório na Rua } \\ \text { DAB } & \text { Departamento de Atenção Básica } \\ \text { DSC } & \text { Departamento de Saúde Coletiva } \\ \text { EqAB } & \text { Equipe de Atenção Básica } \\ \text { ESF } & \text { Estratégia da Saúde da Família } \\ \text { eSF } & \text { Equipe de Saúde da Família } \\ \text { FS } & \text { Faculdade de Ciências da Saúde } \\ \text { IDH } & \text { Índice de Desenvolvimento Humano } \\ \text { MS } & \text { Ministério da Saúde } \\ \text { NASF } & \text { Núcleos de Apoio à Saúde da Família } \\ \text { OMS } & \text { Organização Mundial da Saúde } \\ \text { PAB } & \text { Piso de Atenção Básica } \\ \text { PACS } & \text { Programa de Agentes Comunitários de Saúde } \\ \text { PBF } & \text { Programa Bolsa Família } \\ \text { PMAQ-AB } & \text { Programa de Melhoria do Acesso e da Qualidade na Atenção } \\ & \text { Básica } \\ \text { PNAB } & \text { Política Nacional de Atenção Básica } \\ \text { PNAD } & \text { Pesquisa Nacional por Amostra de Domicílios } \\ \text { PSF } & \text { Programa Saúde da Família } \\ \text { RAS } & \text { Rede de Atenção à Saúde } \\ \text { Requalifica UBS } & \text { Programa de Requalificação de Unidades Básicas de Saúde } \\ \text { SAMU } & \text { Serviço Móvel de Urgência e Emergência } \\ \text { SUS } & \text { Sistema Único de Saúde } \\ \text { UBS } & \text { Unidade Básica de Saúde } \\ \text { UFRGS } & \text { Universidade Federal do Rio Grande do Sul } \\ \text { UnB } & \text { Universidade de Brasília } \\ \text { US } & \text { Unidade de Saúde } \\ & \\ & \end{array}$




\section{SUMÁRIO}

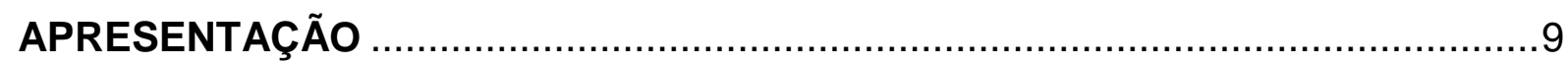

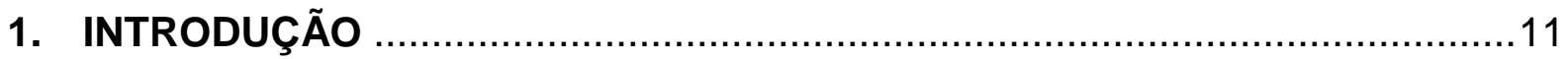

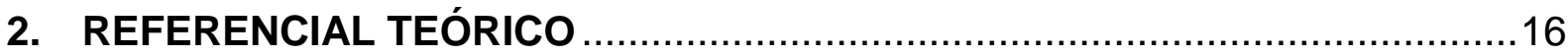

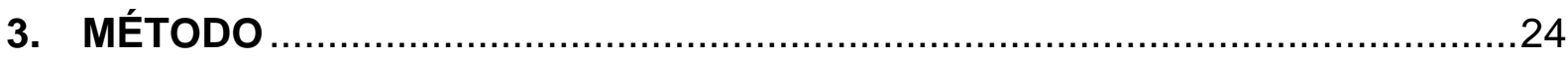

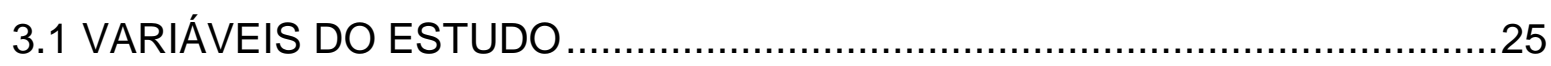

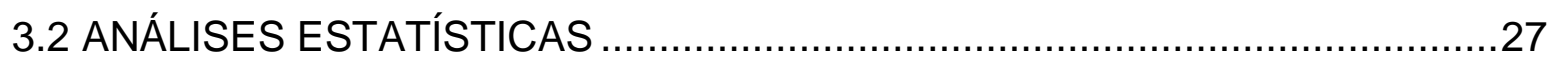

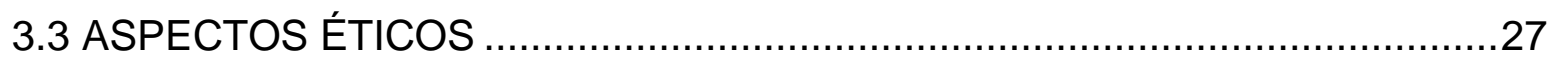

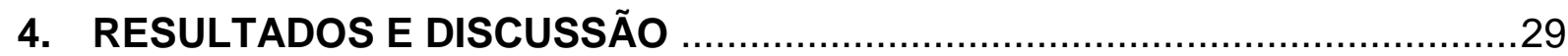

ARTIGO 1: AS DIMENSÕES DA ACESSIBILIDADE EM SAÚDE: COMO AVALIAM OS USUÁRIOS DA ATENÇÃO BÁSICA? ................................................ ARTIGO 2: A AVALIAÇÃO DOS USUÁRIOS DA ATENÇÃO BÁSICA QUANTO À INTEGRALIDADE, À LONGITUDINALIDADE E À COORDENAÇÃO DO

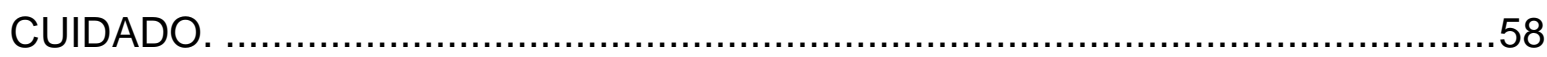

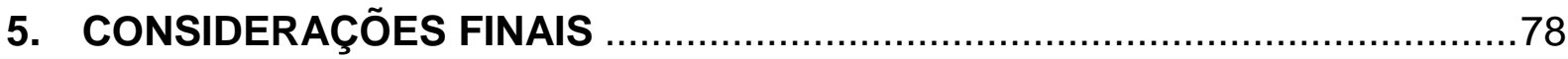

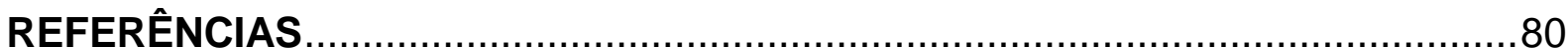

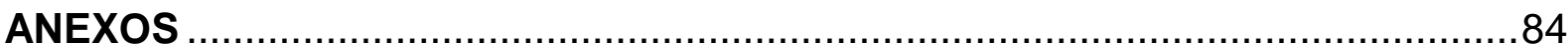

ANEXO A - COMPROVANTE DE SUBMISSÃO DO ARTIGO À REVISTA CADERNOS DE SAÚDE PÚBLICA ....................................................... 84 ANEXO B - COMPROVANTE DE SUBMISSÃO DO ARTIGO À REVISTA CIÊNCIA

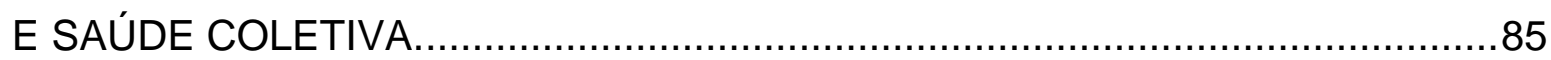

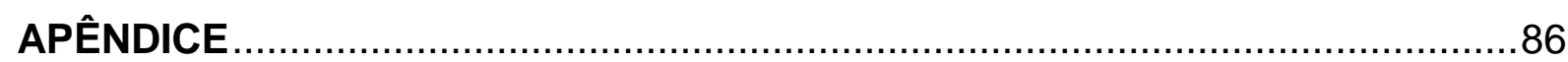

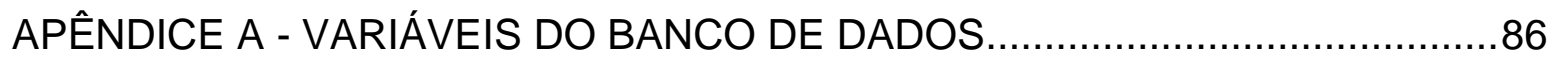




\section{APRESENTAÇÃO}

A Atenção Básica $(A B)$ vem sendo nos últimos anos bastante impulsionada por meio de estratégias de ampliação da sua cobertura no país e já demonstra resultados importantes na redução da mortalidade infantil e no controle das doenças infectocontagiosas. Além disso, foram investidos recursos para melhorar a estrutura das unidades de saúde e para a informatização e conectividade, visando melhores condições de trabalho para os profissionais de saúde, com ambiência acolhedora e mais instrumentos para a gestão do cuidado. Nesse sentido, faz-se necessária agora a análise do cuidado produzido nestes espaços, lançando mão dos instrumentos de avaliação existentes, principalmente com relação às impressões da população usuária destes serviços.

A escolha pelo tema surgiu da minha experiência enquanto enfermeira e trabalhadora na Atenção Básica, em unidades de saúde, durante também minha experiência na formação de graduandos de medicina e enfermagem, em que atuei como facilitadora da aprendizagem em Saúde Coletiva, com ênfase na Atenção Básica, além da minha atual inserção profissional, como trabalhadora no Departamento de Atenção Básica no Ministério da Saúde (DAB/MS), em uma coordenação voltada para a gestão, formulação e apoio à implementação das políticas e programas na área da saúde. $O$ interesse em estudar a percepção da população usuária da $A B$ foi tornando-se cada vez mais evidente, sobretudo na perspectiva de conduzir a gestão, atenção e formação mais direcionada às reais necessidades de saúde das pessoas.

Como organização, esta dissertação foi estruturada em três partes. A primeira aborda as questões conceituais da Atenção Primária à Saúde (APS), que no Brasil foi consensualmente denominada de Atenção Básica. Em seguida, discorremos sobre a Política Nacional de Atenção Básica (PNAB) e o instrumento de avaliação utilizado no estudo, além da relevância do uso da avaliação para a tomada de decisão e para o planejamento das ações.

A segunda parte do estudo trata do percurso metodológico utilizado e a terceira apresenta os resultados através dos dois artigos submetidos à publicação em periódicos na área da Saúde Coletiva. 
Os dois artigos descrevem os resultados da avaliação dos usuários participantes do primeiro ciclo do Programa de Melhoria do Acesso e da Qualidade na Atenção Básica (PMAQ-AB), sendo o primeiro utilizando as variáveis que se referem às dimensões da acessibilidade, observando os resultados e colocando-os em contraste com as características sociodemográficas e o segundo artigo descreve as variáveis relacionadas aos atributos essenciais da APS: integralidade, longitudinalidade e coordenação do cuidado. Ambos os estudos apresentam os resultados da avaliação dos usuários nas cinco macrorregiões do Brasil.

Por fim, é apontado, com as considerações finais, o reconhecimento das iniciativas e avanços alcançados nos últimos anos em ampliar o acesso e qualificar o cuidado a partir da $\mathrm{AB}$. Considerando também a importância de práticas de gestão, formação e atenção mais voltadas às necessidades das pessoas que utilizam os serviços de saúde, com atenção às diferenças locorregionais e da importância em fomentar a prática da avaliação no cotidiano dos profissionais de saúde. 


\section{INTRODUÇÃO}

A partir da Constituição Federal de 1988, o Sistema Único de Saúde (SUS) é formulado com importante papel de impulsionar a participação da população em direção aos seus direitos à saúde. A saúde passa a ser concebida como direito do cidadão e dever do Estado (PAIM et al., 2011).

Diversos avanços são percebidos desde então, como o maior acesso à saúde através de um aumento significativo na cobertura de $A B$ no Brasil, assim como na universalização de ofertas de saúde, a exemplo da imunização, Serviço Móvel de Urgência e Emergência (SAMU), bem como ações de vigilância em saúde, ciência e tecnologia, entre outras, resultando em uma redução importante na morbidade e mortalidade, sobretudo, em relação aos agravos infectocontagiosos. No entanto, com a mudança no perfil sociodemográfico, epidemiológico e nutricional do Brasil, em algumas regiões seguindo o padrão de países desenvolvidos, mas mantendo em algumas localidades o padrão de problemas de saúde e sociais de países subdesenvolvidos, torna-se ainda mais desafiante que as políticas e ações de saúde estejam direcionadas às necessidades diversas da população e atentas à avaliação dos usuários.

Com vistas a uma organização e reordenamento no SUS, a $A B$ vem sendo cada vez mais impulsionada no Brasil, sobretudo a partir de diversos estudos que revelam o impacto na saúde da população em países em que os serviços de saúde são ordenados a partir da AB (STARFIELD, 2002; ALMEIDA, et al, 2013; MACINKO; LIMA COSTA, 2012; MACINKO; HARRIS, 2015).

Em estudo ecológico realizado em 1960, e reeditado com ampliação de amostra em 2001 (GREEN et al., 2001), foi constatado que para uma população de 1.000 indivíduos a cada mês 800 apresentarão algum sintoma, desses, 217 terão sintomas de intensidade que os levaria a acessar o sistema de saúde através de uma unidade de atenção primária. Destas 217, apenas oito pessoas seriam encaminhadas para um hospital secundário ou para um ambulatório de especialidades e, somente, uma necessitaria dar entrada em um hospital terciário.

Outro estudo revelou que países com APS forte (como a Inglaterra, Espanha, Canadá) apresentam melhores indicadores de saúde com menores investimentos, 
comparados a países com APS fraca (como os Estados Unidos) (MACINKO, et al, 2003). Diversos estudos realizados no Brasil (FACCHINI et al., 2006; AQUINO, OLIVEIRA, BARRETO, 2009; MACINKO et al., 2006; BEZERRA FILHO et al., 2007; MACINKO et al., 2007; FACCHINI et al., 2008) revelaram efeitos importantes da APS, especialmente da Estratégia Saúde da Família (ESF), na melhoria da saúde da população.

No Brasil, a Atenção Básica é desenvolvida com alto grau de descentralização, capilaridade e próxima da vida das pessoas. Tem por premissa ser o contato preferencial dos usuários e o centro de comunicação com toda a Rede de Atenção à Saúde (RAS). Portanto, é importante sua orientação pelos princípios da universalidade, da acessibilidade, do vínculo, da continuidade do cuidado, da integralidade da atenção, da responsabilização, da humanização, da equidade e da participação social (STARFIELD, 2002; BRASIL, 2012a).

Para atender a esses princípios, um elemento importante na garantia de acesso a uma atenção de qualidade configura-se na existência de Unidades Básicas de Saúde (UBS) instaladas mais próximas de onde as pessoas vivem, mas também em ofertas adequadas às singularidades dos contextos e especificidades locais e regionais. O Decreto Presidencial no 7.508 de 29 de junho de 2011 traz, dentre outros tantos avanços, o Contrato Organizativo de Ação Pública (COAP) que apresenta a possibilidade de avançar num modo de financiamento mais completo, tendo em vista estas questões (BRASIL, 2011a).

A partir do aumento dos recursos, equivalente a 40\% entre o período de 2010 a 2012, desde a criação do Piso de Atenção Básica (PAB), a PNAB guarda coerência com o Decreto supracitado, ao reconfigurar o financiamento federal da Atenção Básica, de modo a correlacionar equidade e qualidade, levando em consideração a contratualização de compromissos, além do monitoramento de indicadores e o alcance de resultados (BRASIL, 2012a).

Em relação à equidade, há a distinção de valor per capita por município (PAB fixo), de modo a proteger o município menor, com menor densidade demográfica e com vulnerabilidades, como, por exemplo, o elevado percentual da população em pobreza ou extrema pobreza. Quanto à qualidade, tem-se a indução na mudança de 
modelo através da Estratégia Saúde da Família e de programas que avaliem a implantação de processos e a melhoria de resultados, como o Programa de Melhoria do Acesso e Qualidade na Atenção Básica (PMAQ-AB). Este último relaciona-se ainda com a necessidade do SUS em produzir informações estratégicas para a gestão, despontando, entre essas, os resultados de avaliações bem estruturadas, periódicas e contínuas, produtos de um sistema de avaliação (REIS, OLIVEIRA, SELLERA, 2012; BRASIL, 2011b; 2011c).

Nesse contexto, o PMAQ-AB busca melhorar o acesso e qualificar os serviços nesse nível de atenção, bem como permitir a caracterização das ações e serviços prestados. O PMAQ-AB, instituído em 2011 pelo Ministério da Saúde, procura induzir a instituição de processos que ampliem a capacidade das gestões federal, estaduais e municipais, além das equipes de atenção básica, em ofertarem serviços que assegurem maior acesso e qualidade de acordo com as necessidades concretas da população e com garantia de um padrão de qualidade comparável nacional, regional e localmente (REIS, OLIVEIRA, SELLERA, 2012; BRASIL, 2011d; 2012c).

Em seu primeiro ciclo, o PMAQ-AB apresentou a abrangência e adesão de $70 \%$ dos municípios brasileiros, com adesão espontânea de $50 \%$ de suas equipes de Atenção Básica (EqAB) à avaliação externa (AE), equivalente a 17.202 equipes de saúde da família (eSF) no Brasil em 2012.

A partir do instrumento utilizado, além de informações relacionadas à infraestrutura das unidades, insumos e materiais, processo de trabalho e organização e articulação do cuidado junto à RAS, foi possível obter informações relacionadas às experiências e opiniões dos usuários quanto à utilização e satisfação dos serviços da $A B$. No momento da $A E$ foram entrevistados 65.391 usuários em 3.944 municípios brasileiros.

E nesse sentido, a existência de instrumentos de avaliação da percepção das pessoas que utilizam os serviços de saúde é fundamental para a análise e planejamento das ações em saúde. Poder contar com a percepção do usuário, em relação à atenção prestada pela eSF de referência, corrobora por fortalecer a participação da sociedade nas decisões tomadas pelo Estado no interesse geral, 
inserindo o cidadão e o usuário no centro do processo de avaliação (CREVELIM, 2005), proporcionando, assim, benefícios à população a partir de ações e projetos em saúde. Portanto, a opinião dos usuários quanto à qualidade da atenção é considerada de extrema relevância quando se busca avaliar e contribuir com a melhoria dos serviços de saúde (MOIMAZ et al, 2010).

Assim, entendendo o importante papel da $A B$ no cuidado à população, capaz de responder pela maior parte das suas necessidades de saúde, cuja cobertura vem sendo ampliada nos últimos anos, principalmente com a Estratégia Saúde da Família, é estratégico conhecer os resultados da avaliação dos usuários que participaram do PMAQ_AB, quanto à utilização dos serviços da $A B$, tendo em vista que o estudo teve abrangência nacional e poderá apontar questões importantes para a melhoria da qualidade da $\mathrm{AB}$ no Brasil. Portanto, pergunta-se:

- Como os usuários que participaram da avaliação externa do PMAQ-AB avaliam as dimensões da acessibilidade em saúde da Atenção Básica?

- Há diferenças da avaliação das dimensões da acessibilidade nas diferentes macrorregiões do Brasil?

- Como os usuários que participaram da avaliação externa do PMAQ-AB avaliam os atributos de integralidade da atenção, a longitudinalidade e a coordenação do cuidado?

Assim, o presente estudo descreve e analisa os resultados da avaliação dos usuários em saúde participantes do PMAQ-AB que utilizaram os serviços da $A B$ no ano de 2012. Para tanto, foram definidos os seguintes objetivos específicos:

- Descrever a avaliação dos usuários que participaram do PMAQ-AB, em 2012, quanto às dimensões da acessibilidade em saúde, considerando as macrorregiões do Brasil.

- Descrever a avaliação dos usuários que participaram do PMAQ-AB, em 2012, quanto aos atributos essenciais da APS de integralidade, longitudinalidade e coordenação do cuidado, considerando as macrorregiões do Brasil. 
- Analisar os dados do PMAQ-AB, quanto à avaliação dos usuários participantes, quanto aos atributos essenciais da APS de acesso, integralidade, longitudinalidade e coordenação do cuidado, considerando as macrorregiões do Brasil. 


\section{REFERENCIAL TEÓRICO}

A denominação "Atenção Primária à Saúde" (APS) vem se constituindo ao longo das últimas décadas. Comumente, é entendida como uma atenção ofertada por unidades de saúde, não especializadas, com ações clínicas de baixa densidade tecnológica, devendo ser a porta de entrada preferencial das pessoas usuárias dos serviços de saúde, podendo responder pela maior parte dos problemas de saúde de uma população. Porém, há diferentes entendimentos no emprego desse conceito.

Existem países em que a APS é compreendida de modo seletivo com cesta restritiva de serviços, direcionada a grupos populacionais de baixa renda, não garantindo acesso aos demais recursos do sistema (CONILL, 2008). Em outros, ela é concebida de modo abrangente, como modelo de atenção e de organização do sistema de saúde (STARFIELD, 2002). Em vários países europeus, assim como também no Canadá, a APS é responsável por ofertar serviços clínicos de qualidade, além de coordenar o cuidado e organizar o sistema.

Como marco histórico da APS, podemos referir o Relatório Dawson, em 1920, que em 1948 influenciou a criação do Sistema Nacional de Saúde britânico e a Declaração de Alma-Ata, na União Soviética, em 1978. O primeiro traz uma das perspectivas iniciais de organização dos serviços de saúde de modo regionalizada e hierarquizada e com definição territorial. Já em Alma-Ata, com a "Conferência Internacional sobre Cuidados Primários de Saúde", foi elaborada uma declaração resguardando questões importantes, conforme é possível observar no fragmento abaixo:

\footnotetext{
Atenção essencial à saúde baseada em métodos e tecnologias práticas, cientificamente bem fundamentadas e socialmente aceitáveis, colocadas ao alcance universal de indivíduos e famílias da comunidade, mediante sua plena participação e a um custo que a comunidade e o país possam manter em cada fase de seu desenvolvimento, no espírito de autoconfiança e automedicação. Fazem parte integrante tanto do sistema de saúde do país, do qual constituem a função central e o foco principal, quanto do desenvolvimento social e econômico global da comunidade. Representam o primeiro nível de contato dos indivíduos, da família e da comunidade com o sistema nacional de saúde, pelo qual os cuidados de saúde são levados o mais proximamente possível aos lugares onde pessoas vivem e trabalham, e constituem o primeiro elemento de um continuado processo de assistência à saúde (OMS, 1978, p. 1-2).
} 
Segundo Starfield (2002), a APS incorpora em sua formulação quatro atributos essenciais, que, muitas vezes, se correlacionam e complementam-se. São esses:

A atenção ao primeiro contato, que reflete a acessibilidade e uso do serviço a cada novo problema ou novo evento de um problema que leva o indivíduo a procurar o serviço de saúde. Para ser reconhecido como primeiro contato este espaço deverá ser percebido pelos usuários como acessível e assim refletir na sua utilização.

Longitudinalidade, que se pressupõe a atenção à saúde e o cuidado ao longo do tempo, sendo a APS capaz de identificar os indivíduos, família ou comunidade que deverão ser atendidos, tendo o vínculo como elemento fundamental produzindo cooperação mútua entre as pessoas e os profissionais de saúde.

Integralidade, em que a APS realiza arranjos de modo que as pessoas que dela utilizam recebam todos os serviços de atenção à saúde, sejam estes de ordem funcional, orgânica ou social, mesmo quando não for possível serem ofertados neste nível de atenção.

Coordenação do cuidado, que implica na continuidade, seja por parte dos profissionais ou de documentos que revelem a atenção prestada (prontuários, por exemplo) e ainda da associação de ambos, a partir do reconhecimento de problemas ou de necessidades.

Além dos atributos essenciais, a APS considera também três atributos derivados que qualificam as ações e serviços desse nível de atenção: a atenção à saúde centrada na família, a orientação comunitária e a competência cultural.

No Brasil, a partir da década de 90, após a constituição do SUS, uma nova forma de organização dos serviços de saúde foi sendo estruturada no país e em algum momento com medidas do governo direcionadas à perspectiva de induzir a orientação do sistema a partir da APS (ESCOREL et al., 2007), que convencionalmente no país passou a ser denominada de Atenção Básica à Saúde (ABS). 
Diversos esforços foram empregados pela gestão federal na perspectiva de mudança das práticas de saúde voltadas à atenção especializada e hospitalar, oriundas da medicina previdenciária, buscando $O$ investimento no sentido de impulsionar programas e políticas centrados na $A B$, influenciado também pela doutrina de cuidados primários de saúde da Conferência de Alma-Ata.

E após experiências bem-sucedidas em algumas regiões do país, em 1991 é criado o Programa de Agentes Comunitários de Saúde (PACS), que em seguida evolui para o Programa de Saúde da Família (PSF) (PAIM et al, 2011; TANAKA, RIBEIRO, 2009; SOUSA, 2007).

O PSF, inicialmente projetado para garantir acesso assistencial às áreas de maior vulnerabilidade social, ganha centralidade na agenda governamental e, em 2006, passa a ser denominado como Estratégia Saúde da Família (ESF), fundamentada através da Política Nacional de Atenção Básica (PNAB), passando a ser considerada como estratégia de reorientação do modelo assistencial à saúde, induzindo uma nova dinâmica na organização dos serviços e ações de saúde (PAIM et al, 2011; TANAKA, RIBEIRO, 2009; SOUSA, 2007).

Segundo a PNAB, aprovada através da Portaria ํㅡ 2.488 de 21 de outubro de 2011, a Atenção Básica compreende ações de saúde direcionadas ao indivíduo e à coletividade com abrangência voltada à promoção e à proteção da saúde, à prevenção de agravos, ao diagnóstico, ao tratamento, à reabilitação, à redução de danos e à manutenção da saúde em busca da atenção integral, produzindo impactos na situação de saúde da população, nos determinantes e condicionantes de saúde, além de buscar a autonomia das pessoas (BRASIL, 2012a).

É desenvolvida com o mais alto grau de descentralização e capilaridade, próxima da vida das pessoas. Deve ser o contato preferencial dos usuários, a principal porta de entrada e centro de comunicação da RAS (STARFIELD, 2002; BRASIL, 2012a).

Mesmo sendo uma estratégia em construção, com impulso significativo na expansão da cobertura nacional, diversos esforços têm sido produzidos para ampliar o acesso e a qualidade do cuidado nesse ponto da atenção, a exemplo dos Núcleos de Apoio à Saúde da Família (NASF), do Programa Nacional Telessaúde Brasil 
Redes na Atenção Básica, dos Consultórios na Rua (CnaR), do Programa de Requalificação de Unidades Básicas de Saúde (Requalifica UBS), dentre outros, trazendo a necessidade de aprofundar a discussão sobre acesso e qualidade da atenção no SUS, considerando seus avanços, mas também seus desafios.

Quanto ao conceito de acesso, em 1974 o termo foi definido considerando as características da população e as questões relacionadas ao território, porém, definindo-o também como ideia política (ADAY, ANDERSEN, 1974). Em 1973, em um estudo, foi avaliado que há relação entre os determinantes individuais e sociais no acesso à saúde (ANDERSEN, NEWMAN, 2005). O acesso também foi definido como o grau de interação entre as pessoas que utilizam os serviços e o sistema de saúde, a partir de um estudo que avaliou, através de indicadores de resultado, a satisfação dos usuários dos serviços (PENCHANSKY, THOMAS, 1981).

Alguns autores, como Donabedian, empregam o termo acessibilidade caráter ou qualidade do que é acessível - ao invés de acesso - ato de ingressar, entrada - por considerarem que a acessibilidade está relacionada para além do ingresso ou entrada do indivíduo ao serviço de saúde, mas, sobretudo, à capacidade existente de produzir ofertas e de responder às necessidades de saúde de uma determinada população, observando as características dos serviços e dos recursos de saúde que auxiliam ou são obstáculos da utilização pelos indivíduos (DONABEDIAN, 1973). Donabedian descreveu dois aspectos para a acessibilidade. Um refere-se às questões socio-organizacionais (sociocultural, educacional, econômica) e o outro ao aspecto geográfico (distância física e barreiras geográficas entre o usuário e os serviços).

$\mathrm{E}$ as questões referentes à acessibilidade incidem diretamente com a qualidade da atenção em saúde prestada. Nesse sentido, o conceito de qualidade possui natureza objetiva e subjetiva e a avaliação da qualidade em saúde vem ganhando um maior interesse por parte da gestão e nos campos de pesquisa. $\mathrm{Na}$ década de 1960, Donabedian lança uma metodologia avaliativa e classificatória para medir a qualidade dos serviços, referente à estrutura, ao processo e aos resultados nos serviços de saúde, a partir de critérios de juízo de valor e objetivos de um sistema de saúde e da sociedade do qual ele faz parte (DONABEDIAN, 1980). 
A partir dos anos 80 , iniciaram-se estudos e investigações que extrapolam a análise dos custos das atividades em relação à saúde, compreendendo, também, a qualidade e a satisfação dos usuários dos serviços. Como fatores de influência na busca do entendimento e avaliação da qualidade estão: a busca pelo uso eficiente dos recursos, o maior envolvimento da população na avaliação dos serviços a partir da sua participação no financiamento, bem como a busca pela redução das demandas judiciais de usuários insatisfeitos, além da necessidade de reconhecer o indivíduo de modo integral, reconhecendo a avaliação da satisfação das pessoas (SERAPIONI, 1999).

Conhecer a avaliação de satisfação dos usuários, a conformação dos serviços e as especificidades locais são elementos essenciais na avaliação da qualidade e dos benefícios das políticas públicas de saúde (HARTZ, CONTANDRIOPOULOS, 2004).

No Brasil, identificamos estudos de abrangência nacional que buscaram avaliar a qualidade dos serviços de saúde, a partir da satisfação e da utilização dos usuários, porém, com recortes para algumas questões e para a avaliação dos diversos serviços de saúde da rede de atenção (BRASIL, 2014; GOUVEIA et al, 2005). Sendo ainda importante fomentar a realização de estudos de abrangência nacional que aprofundem a avaliação do usuário em relação à Atenção Básica, mas ao mesmo tempo observem questões relacionadas à infraestrutura e avaliação do processo de trabalho junto às equipes de Atenção Básica. Essas questões são fundamentais para subsidiar os gestores na tomada de decisão, formulação e recondução de políticas e na autoavaliação dos profissionais de saúde, no sentido da melhoria da qualidade da atenção.

Com isso, o Departamento de Atenção Básica do Ministério da Saúde (DAB/MS) lança o Programa de Melhoria do Acesso e da Qualidade na Atenção Básica (PMAQ-AB), através da Portaria o 1.654 de 19 de julho de 2011, a qual institui o Programa supracitado no âmbito do SUS, além do incentivo financeiro do PMAQ-AB, denominado Componente de Qualidade do Piso de Atenção Básica Variável - PAB Variável (BRASIL, 2011b; BRASIL, 2012b). 
O objetivo do PMAQ-AB está na indução da ampliação do acesso e na melhoria da qualidade da Atenção Básica, buscando produzir padrão de qualidade comparável nacional, regional e localmente que auxiliem no direcionamento das ações da Atenção Básica. Conta com repasse de incentivo financeiro mensal, baseado no número de equipes de saúde participantes e com cadastro no Programa, bem como nos critérios definidos em Portaria.

Além disso, o PMAQ-AB vem como proposta que se conecta com outras estratégias da gestão federal, entre elas, a $A B$ como porta de entrada preferencial do sistema de saúde e coordenadora da RAS, além do Decreto no 7.508 que sinaliza o redesenho da regionalização do financiamento do SUS e, ainda, de outras estratégias avaliativas e iniciativas (PINTO, SOUSA, FERLA, 2014).

As diretrizes do PMAQ-AB descritas na Portaria nำ1.654 são:

1 - Construir parâmetro de comparação entre as equipes de saúde da atenção básica, considerando-se as diferentes realidades de saúde;

II - Estimular processo contínuo e progressivo de melhoramento dos padrões e indicadores de acesso e de qualidade que envolva a gestão, o processo de trabalho e os resultados alcançados pelas equipes de saúde da atenção básica;

III - Transparência em todas as suas etapas, permitindo-se o contínuo acompanhamento de suas ações e resultados pela sociedade;

IV - Envolver, mobilizar e responsabilizar os gestores federal, estaduais, municipais e do Distrito Federal, as equipes de saúde de atenção básica e os usuários num processo de mudança de cultura de gestão e qualificação da atenção básica;

V - Desenvolver cultura de negociação e contratualização, que implique na gestão dos recursos em função dos compromissos e resultados pactuados e alcançados;

VI - Estimular a efetiva mudança do modelo de atenção, o desenvolvimento dos trabalhadores e a orientação dos serviços em função das necessidades e da satisfação dos usuários; e

VII - Caráter voluntário para a adesão tanto pelas equipes de saúde da atenção básica quanto pelos gestores municipais, a partir do pressuposto de que o seu êxito depende da motivação e proatividade dos atores envolvidos (BRASIL, 2011b).

Em síntese, o Programa estrutura-se em quatro fases dinâmicas e cíclicas, como em um espiral. São estas fases: 1) adesão e contratualização; 2) desenvolvimento (que na verdade deve ser transversal a todo o ciclo); 3) avaliação externa; e 4) certificação e recontratualização (BRASIL, 2011d). 
$\mathrm{Na}$ adesão e contratualização, todas as equipes de $\mathrm{AB}$ (eSF ou de outras modalidades de $A B$ ), incluindo as equipes de saúde bucal, podem de modo voluntário aderir ao PMAQ-AB, a partir da pactuação entre gestores municipais e equipes de saúde. Para esta fase, é necessário que essas equipes estejam em conformidade com os princípios da Atenção Básica e com os critérios definidos no Manual Instrutivo do Programa que, dentre eles, encontram-se os compromissos a serem contratualizados pelas EqAB e pelas gestões municipais.

A fase de desenvolvimento tem como principais estratégias a promoção da autoavaliação, monitoramento de indicadores contratualizados na fase da adesão, educação permanente em saúde e apoio institucional.

$\mathrm{Na}$ avaliação externa ocorre um conjunto de ações que observará questões relacionadas ao acesso e à qualidade dos municípios e equipes da atenção básica participantes do Programa, sendo esta avaliação conduzida por instituições de ensino e/ou pesquisa parceiras do PMAQ-AB.

Com a utilização de um instrumento, composto por diversas variáveis de análise é verificado nas unidades de saúde, junto aos trabalhadores das equipes e usuários dos serviços questões relacionadas ao acesso e à qualidade esperada na Atenção Básica. O instrumento de avaliação externa, em 2012, estava organizado em quatro grandes dimensões (gestão municipal, coordenação da atenção básica, unidade básica de saúde e perfil, processo de trabalho e atenção à saúde) e 12 subdimensões que foram constatadas a partir de documentos existentes na unidade de saúde ou da observação direta do avaliador. O instrumento apresenta em sua estrutura três módulos distribuídos em: 1) observação na unidade de saúde; 2) entrevista com profissional da equipe de $A B$ e verificação de documentos na unidade de saúde; e 3) entrevista na unidade de saúde com usuário (BRASIL, 2012d).

Após a avaliação externa, as equipes são certificadas, de acordo com o seu desempenho, a partir de parâmetros que permitam a comparabilidade entre as equipes pela verificação das médias de desempenho, considerando as dimensões da implementação de processos autoavaliativos, verificação do desempenho alcançado para o conjunto de indicadores contratualizados e, também, da verificação de evidências para um conjunto de padrões de qualidade. 
Os municípios foram distribuídos, neste período, em estratos que consideraram aspectos sociais, econômicos e demográficos buscando assegurar a equidade ao comparar as equipes. A partir da certificação, e com base no desempenho das equipes, uma nova contratualização de indicadores e compromissos podia ser realizada, abrindo novamente o ciclo do Programa.

Dando aqui destaque à avaliação do usuário que utiliza o serviço da $A B$, percebe-se uma indução para a maior participação do usuário dos serviços, sendo este um elemento importante para a análise da qualidade da atenção prestada, visando, assim, maior adequação no uso de serviços de saúde, tanto em relação à estrutura como ao processo do cuidado da saúde. 


\section{MÉTODO}

Trata-se de um estudo descritivo, de abordagem quantitativa, baseado em dados secundários selecionados e gerados a partir do banco de dados, de domínio público e de base nacional, da avaliação externa do primeiro ciclo do PMAQ-AB, realizada em 2012.

As informações foram obtidas por meio de consulta aos microdados do PMAQ no portal do Departamento de Atenção Básica do Ministério da Saúde, disponíveis em meio eletrônico. ${ }^{1}$

O instrumento utilizado para realizar o estudo foi organizado em três módulos (BRASIL, 2011d):

- Módulo I - observação na Unidade Básica de Saúde (UBS) com relação aos aspectos de infraestrutura;

- Módulo II - entrevista com os profissionais (um para cada equipe) sobre processo de trabalho das equipes de Atenção Básica (EqAB), além da constatação de documentos na UBS; e

- Módulo III - entrevista com usuários na UBS sobre sua experiência de uso, condições de acesso, utilização de serviços de saúde e satisfação.

Para a coleta foram selecionados os dados do módulo III, que trata da entrevista com usuários na UBS, com relação a sua experiência referente ao acesso, à utilização dos serviços de saúde e à satisfação (BRASIL, 2011d), sendo delimitado para o estudo o componente referente à utilização dos serviços de saúde pelos usuários que participaram da entrevista. Para definir e selecionar as variáveis foram considerados os atributos da APS essenciais - acesso, integralidade, longitudinalidade e coordenação do cuidado (STARFIELD, 2002).

Para a seleção dos usuários entrevistados foram utilizados como critérios de inclusão no momento da avaliação externa: maioridade, não ter passado pela

\footnotetext{
${ }^{1}$ Microdados disponíveis no Portal da Saúde no link $<$ http://dab.saude.gov.br/portaldab/ape pmaq.php?conteudo=1 ciclo $>$. Acesso em 21 de dezembro de 2015.
} 
consulta ou atendimento antes da entrevista, ter vínculo com a eSF (não sendo aplicado o questionário se aquele fosse o primeiro momento dele com a equipe) e ter realizado pelo menos um atendimento na unidade nos últimos doze meses. Os entrevistadores aplicavam o questionário a quatro usuários por equipe de saúde, que se encontravam na unidade de saúde, considerando os critérios de inclusão e que aceitavam participar do estudo, a partir de termo de consentimento livre e esclarecido.

Participaram do estudo 65.391 usuários, vinculados às equipes de saúde de Atenção Básica com adesão voluntária ao programa naquele ano, correspondendo assim, a 3.944 municípios (70\%) e 17.202 das equipes (53,9\% das equipes de $A B$ no Brasil, em 2012), sendo o estudo composto por equipes de saúde da Família (eSF) e equipes de $A B$ tradicionais. No primeiro ciclo do PMAQ-AB, cada município poderia incluir todas ou apenas parte das suas equipes. Por questões do cronograma de evolução logística, administrativa e orçamentária, foi fixado um teto máximo de adesão de 17.664 equipes de AB/SF no Brasil.

Ao todo participaram do programa, 542 equipes de $A B$ tradicional (23 na região norte, 207 na região nordeste, 45 na região centro oeste, 210 na região sudeste e 57 na região sul) e 16.643 eSF (1.022 na região norte, 5.346 na região nordeste, 1.060 na região centro oeste, 6.355 na região sudeste e 2.860 na região sul).

A distribuição regional dos usuários participantes foi: 3.728 na região Norte, 21.556 na região Nordeste, 4.337 na região Centro-Oeste, 25.406 na região Sudeste e 10.364 na região Sul.

\subsection{VARIÁVEIS DO ESTUDO}

Após a seleção das variáveis foram calculadas as proporções que, posteriormente, foram agregadas às macrorregiões do país, e realizada a caracterização da população estudada, compreendendo as seguintes informações: caracterização sociodemográfica e econômica, gênero, idade, raça/cor, renda e recebimento do Programa Bolsa Família (PBF). 
Para o estudo, voltado para as dimensões da acessibilidade, realizou-se a seleção das variáveis referentes à acessibilidade geográfica e à acessibilidade organizacional/funcional (BRASIL, 2012e).

Acessibilidade geográfica:

a. A unidade de saúde está localizada próxima ou distante da sua residência?

Acessibilidade organizacional/funcional:

a. A unidade de saúde funciona os cinco dias da semana?

b. O horário de funcionamento da unidade de saúde atende às suas necessidades de saúde?

c. Para facilitar o atendimento, o(a) senhor(a) gostaria que a unidade de saúde atendesse em outro horário?

d. O médico está presente na unidade de saúde ou em atividades no bairro durante todos os horários de funcionamento da unidade de saúde?

e. Existe a possibilidade do senhor(a) escolher a equipe que the atende (médico, enfermeiro, agente comunitário de saúde, outros)?

f. Como ocorre a marcação da consulta na sua unidade de saúde?

g. O senhor(a) procurou atendimento quando apresentou problema de saúde que considerou uma urgência?

h. Procurou atendimento nesta unidade de saúde quando apresentou problema que considerou urgência?

i. Por que não procurou esta unidade de saúde para este atendimento?

E para o estudo que trata da avaliação dos usuários quanto aos atributos de integralidade, longitudinalidade e coordenação do cuidado foram selecionadas as variáveis (BRASIL, 2012e): 
a. A equipe de saúde busca resolver as suas necessidades/problemas na própria unidade de saúde?

b. Os profissionais de saúde fazem sempre perguntas sobre outras necessidades de saúde além daquelas relacionadas com o motivo da consulta?

c. Os profissionais da equipe de saúde da $A B$ sempre sugerem soluções adequadas às suas realidades?

d. Nessa unidade o(a) senhor(a) é atendido pelo mesmo médico?

e. Nessa unidade o(a) senhor(a) é atendido pelo mesmo enfermeiro?

f. Os profissionais lembram-se do que aconteceu nas últimas consultas do(a) senhor(a)?

g. Depois que o(a) senhor(a) foi atendido(a) por outros profissionais fora desta unidade de saúde, a equipe conversou com o(a) senhor(a) sobre este atendimento?

h. $O(a)$ senhor(a) encontra facilidade para saber dos resultados dos seus exames que chegam nesta unidade de saúde?

\subsection{ANÁLISES ESTATÍSTICAS}

As descrições dos resultados basearam-se em comparações proporcionais das respostas das variáveis dos questionários, adotando-se como recorte as cinco regiões brasileiras. Os dados foram armazenados e organizados em uma planilha eletrônica do software Microsoft Office Excel 2010 para Windows®. Para os cálculos dos intervalos de confiança das proporções utilizou-se uma significância de 0,05.

\subsection{ASPECTOS ÉTICOS}

Como este estudo utiliza dados secundários, de domínio público, está dispensado de aprovação pelo Comitê de Ética. Os dados foram apresentados agrupados, mantendo-se a confidencialidade sobre as respostas de cada indivíduo e o nome dos usuários entrevistados. Os princípios éticos fundamentais (autonomia, 
beneficência, não-maleficência, justiça, equidade) foram respeitados em todas as etapas da investigação. 


\section{RESULTADOS E DISCUSSÃO}

Os resultados e a discussão serão apresentados no formato de dois artigos:

\section{ARTIGO 1:}

Título: As dimensões da acessibilidade em saúde: como avaliam os usuários da Atenção Básica entrevistados pelo PMAQ-AB. Situação: submetido à revista "Cadernos de Saúde Pública", em 07 de abril de 2016.

Autores: Daniela Cristina Moreira M. de Figueiredo

Helena Eri Shimizu

Walter Massa Ramalho

\section{ARTIGO 2:}

Título: A avaliação dos usuários da Atenção Básica quanto à integralidade, à longitudinalidade e à coordenação do cuidado.

Situação: submetido à revista Ciência e Saúde Coletiva.

Autores: Daniela Cristina Moreira M. de Figueiredo

Helena Eri Shimizu

Walter Massa Ramalho 


\section{ARTIGO 1: AS DIMENSÕES DA ACESSIBILIDADE EM SAÚDE: COMO AVALIAM OS USUÁRIOS DA ATENÇÃO BÁSICA ENTREVISTADOS PELO PMAQ-AB.}

\section{PRIMARY CARE ACCESSIBILITY: HOW TO EVALUATE USERS INTERVIEWED BY PMAQ-AB?}

\section{Autores:}

Daniela Cristina Moreira M. de Figueiredo ${ }^{1}$

Helena Eri Shimizu²

Walter Massa Ramalho ${ }^{3}$

${ }^{1}$ Mestranda em Saúde Coletiva pela Universidade de Brasília (UnB). Consultora Técnica do Departamento de Atenção Básica do Ministério da Saúde. Endereço: SQS 306, bloco K, apto 403. Brasília, Distrito Federal. CEP: 70353-110. Telefone: (61) 8109-8816. E-mail: dla.moreira@yahoo.com.br

2 Doutora em Enfermagem pela Universidade de São Paulo. Professora Adjunta do Departamento de Saúde Coletiva (DSC) da Faculdade de Ciências da Saúde (FS) da Universidade de Brasília (UnB). Brasília, Distrito Federal. Telefone: (61) 3072-115. E-mail: Shimizu@unb.br

${ }^{3}$ Doutor em Medicina Tropical pela Universidade de Brasília. Professor Adjunto da UnB - Faculdade de Ceilândia, curso Gestão em Saúde / Área de Epidemiologia. Endereço: QNN 14 Área Especial - Ceilândia Sul CEP: 72220-140. Brasília, Distrito Federal. E-mail: Walter.ramalho@gmail.com 


\section{RESUMO}

O artigo tem por objetivo analisar as dimensões da acessibilidade na Atenção Básica na perspectiva dos usuários no Brasil. Estudo transversal de caráter descritivo, multicêntrico, a partir dos dados secundários, da Avaliação externa do Programa Nacional de Melhoria do Acesso e da Qualidade da Atenção Básica, com a participação de 65.391 usuários. Os dados revelaram que as distâncias geográficas ainda são barreiras importantes, sobretudo na região norte do país, assim como a ausência do profissional médico em todos os turnos e a impossibilidade na escolha dos profissionais. Embora existam estratégias e instrumentos que induzem o acesso aos serviços, ainda são evidentes as barreiras de acessibilidade organizacional, onde 0 acesso à unidade se dá a partir de fichas e filas e onde a população não reconhece a Atenção Básica como espaço para os atendimentos de urgência. Sendo este nível de atenção o contato preferencial da população para a maioria das suas necessidades de saúde faz-se necessário observar essas questões consideradas como obstáculos de acessibilidade, com atenção para os comportamentos dessas dimensões nas distintas regiões do país, em busca de uma Atenção Básica mais acessível, cuidadora e resolutiva, além de sensível às necessidades e avaliação da população usuária dos serviços de saúde.

Área de concentração: Saúde Coletiva

Palavras-chave: Acesso aos serviços de saúde; Atenção Primária à Saúde; Avaliação em saúde.

Keywords: Health Services Accessibility; Primary Health Care; Health Evaluation.

\section{INTRODUÇÃO}


A Atenção Primária à Saúde (APS) ou Atenção Básica (AB) como é denominada no Brasil, é considerada a porta de entrada preferencial de uma rede de atenção à saúde ${ }^{1}$. Para ser assim reconhecida é preciso que o acesso ou acessibilidade do usuário, na utilização dos serviços que atendam às suas necessidades em saúde, tenham o mínimo de barreiras possível, e que as diversas dimensões sejam observadas e compreendidas.

Enquanto conceito, alguns autores adotaram, a exemplo de Donabedian ${ }^{2}$, o termo acessibilidade que será também tomado neste artigo, cuja definição está relacionada para além do ingresso ou entrada do individuo ao serviço de saúde, mas, sobretudo, à capacidade existente de produzir ofertas e de responder às necessidades de saúde de uma determinada população, observando-se as características dos serviços e dos recursos de saúde que auxiliam ou são obstáculos para utilização pelos indivíduos. Para este autor, existem duas dimensões da acessibilidade que devem ser consideradas: a dimensão geográfica e a dimensão organizacional/funcional. A primeira está mais relacionada ao espaço, à distância e ao tempo, além dos custos para o deslocamento deste indivíduo até o local em que procura uma determinada atenção. Já a segunda dimensão inclui as demais características de oferta de serviços (organização das agendas dos profissionais, ações que selecionam as pessoas por condição social ou pelo diagnóstico), que facilitam ou impedem o uso das pessoas quando deles necessitam.

Esse conceito se aproxima da análise apresentada por Starfield ${ }^{3}$ quanto ao acesso e obstáculos enfrentados pelos usuários na utilização dos serviços da APS, estando relacionados com a localização, os horários de funcionamento das unidades e a disponibilidade dos profissionais para consultas programadas ou de demanda espontânea. Além desses, a realização ou não de ações como: o estudo do território, a avaliação das necessidades de saúde e do risco e vulnerabilidade da população, com priorização das ações dos profissionais, considerando os determinantes e condicionantes do processo saúde doença (modo de viver, habitação, ambiente, trabalho, educação, lazer, cultura e bens e serviços essenciais), podem influenciar na acessibilidade da população ao serviço de saúde.

Para a autora, todo sistema de saúde deve ter como meta, além do emprego de métodos e estratégias avançadas de conhecimento e manejo das enfermidades e 
maximização da saúde, também, e de igual importância, a garantia de que as disparidades entre os grupos populacionais sejam minimizadas, de modo a não existir desvantagens em relação ao acesso dos mesmos, aos serviços de saúde e ao alcance de um ótimo nível de saúde.

Estudos revelam aumento no acesso e na utilização dos serviços de saúde no Brasil, sobretudo na população urbana (mesmo que com percentual ainda inferior ao observado em outros países) ${ }^{4-6}$, além do reconhecimento pela população usuária da Estratégia Saúde da Família (ESF) enquanto serviço de AB de mais fácil acesso, melhor qualidade e com maior satisfação em comparação às unidades de $A B$ tradicionais $^{6-7}$.

Embora existam diversas publicações ${ }^{8-11}$ com recortes direcionados à análise do acesso e acessibilidade em saúde, boa parte das mesmas está voltada para experiências específicas de uma determinada localidade e de acesso aos serviços de saúde de modo geral, sendo oportuno contemplar os estudos que representem as diversidades regionais de um país continental como o Brasil, sob a ótica da população que utiliza os serviços de saúde e ainda, voltados para a $A B$, que é considerada a porta de entrada preferencial do sistema de saúde.

Nesse aspecto, os métodos que avaliam as dimensões da acessibilidade em saúde são desejáveis, uma vez que poderão melhor direcionar a elaboração de políticas públicas que estejam alinhadas com as necessidades de saúde, buscando superar as dificuldades de utilização dos indivíduos e comunidades, sobretudo, se considerarem a avaliação dos usuários destes serviços.

Desse modo, o Ministério da Saúde, em acordo tripartite e em parceria com algumas Instituições de Ensino Superior, instituiu o Programa Nacional de Melhoria do Acesso e da Qualidade da Atenção Básica (PMAQ-AB), que teve como objetivo induzir a instituição de processos que ampliem a capacidade das gestões federal, estaduais e municipais, além das equipes de $A B$, em ofertarem serviços que assegurem maior acesso e qualidade, de acordo com as necessidades concretas da população, com garantia de um padrão de qualidade comparável nacional, regional e localmente ${ }^{12}$. 
Em sua estrutura, o PMAQ contou com quatro fases, sendo uma delas a avaliação externa, responsável pela coleta de informações relacionadas à infraestrutura das unidades, insumos e materiais, processo de trabalho e organização, articulação do cuidado junto à rede de atenção à saúde, além de informações relacionadas às experiências e opiniões dos usuários quanto à acessibilidade, utilização e satisfação dos serviços da Atenção Básica $(A B)^{12}$.

Nesse sentido, buscando conhecer a percepção dos usuários da $A B$ com relação à acessibilidade em saúde, surgiu como questão:

Como os usuários que participaram da avaliação externa do PMAQ $A B$ avaliam os aspectos relacionados às dimensões da acessibilidade?

Assim, o presente estudo busca descrever as dimensões da acessibilidade na Atenção Básica, a partir da perspectiva dos usuários que participaram da Avaliação externa do PMAQ-AB, no ano de 2012, bem como explorar, como a percepção dos usuários se apresenta nacionalmente e nas macrorregiões do país, tendo em vista as diversidades loco-regionais.

\section{MÉTODO}

Trata-se de um estudo transversal, de caráter descritivo, que utilizou dados secundários, de domínio público, a partir do Programa de Melhoria do Acesso e da Qualidade na Atenção Básica (PMAQ-AB), mais especificamente da avaliação externa em seu primeiro ciclo, realizada em 2012.

As informações foram obtidas por meio de consulta dos microdados do PMAQ, no portal do Departamento de Atenção Básica do Ministério da Saúde disponíveis publicamente em meio eletrônico.

Foram utilizados os dados do módulo III, que trata da entrevista com usuários na Unidade Básica de Saúde (UBS), com relação a sua experiência no acesso, utilização dos serviços de saúde e satisfação, sendo delimitado como recorte o componente referente à utilização dos serviços de saúde pelos usuários que participaram da entrevista. 
Os critérios de inclusão dos sujeitos do estudo foram: usuários dos serviços de saúde na Atenção Básica, no Brasil, considerando maioridade, não ter passado pela consulta ou atendimento antes da entrevista, ter vínculo com a equipe de Saúde da Família (não sendo aplicado o questionário se aquele fosse o primeiro momento dele com a equipe) e ter realizado pelo menos um atendimento na unidade nos últimos doze meses.

Participaram do estudo 65.391 usuários, vinculados às equipes de saúde de Atenção Básica com adesão voluntária ao programa naquele ano, correspondendo assim, a 3.944 municípios (70\%) e 17.202 das equipes (53,9\% das equipes de $A B$ no Brasil, em 2012), sendo o estudo composto por equipes de saúde da Família (eSF) e equipes de AB tradicionais. No primeiro ciclo do PMAQ-AB, cada município poderia incluir todas ou apenas parte das suas equipes. Por questões do cronograma de evolução logística, administrativa e orçamentária, foi fixado um teto máximo de adesão de 17.664 equipes de AB/SF no Brasil.

Ao todo participaram do programa, 542 equipes de $A B$ tradicional (23 na região norte, 207 na região nordeste, 45 na região centro oeste, 210 na região sudeste e 57 na região sul) e 16.643 eSF (1.022 na região norte, 5.346 na região nordeste, 1.060 na região centro oeste, 6.355 na região sudeste e 2.860 na região sul).

A distribuição regional dos usuários participantes foi: 3.728 na região Norte, 21.556 na região Nordeste, 4.337 na região Centro-Oeste, 25.406 na região Sudeste e 10.364 na região Sul.

\section{Variáveis do estudo}

Caracterização sócio demográfica e econômica da população estudada: gênero; idade; raça/cor, e; renda; recebimento do programa bolsa família.

Acessibilidade geográfica: percepção da distância entre a unidade de saúde e a residência.

Acessibilidade organizacional/funcional: horário de funcionamento; dias de funcionamento; outros horários de funcionamento da unidade; presença do médico na UBS ou em atividade no bairro, durante todos os horários de funcionamento do 
serviço; possibilidade de escolha da equipe por parte do usuário; formas de marcação de consultas; e, atendimento de urgência nas UBS.

\section{Análises estatísticas}

As descrições dos resultados basearam-se em comparação proporcionais das respostas das variáveis dos questionários, adotando-se como recorte, as cinco regiões brasileiras. Os dados foram armazenados e organizados em uma planilha eletrônica Microsoft Office Excel 2010 para Windows®. Para os cálculos dos intervalos de confiança das proporções, utilizou-se uma significância de 0,05. 


\section{RESULTADOS}

$\mathrm{Na}$ tabela 1 estão apresentadas as distribuições relativas às características sociodemográficas (gênero, idade, raça/cor) e econômica (renda) dos usuários, a nível nacional e por macrorregião do país.

Tabela 1 - Distribuição das características demográficas (gênero, idade e raça/cor) e econômicas (renda), da população estudada. Brasil e regiões, 2012.

(continua)

\begin{tabular}{|c|c|c|c|c|c|c|}
\hline Variável & $\begin{array}{c}\text { Norte } \\
\text { n (\%) } \\
{[\text { IC95\%] }}\end{array}$ & $\begin{array}{c}\text { Nordeste } \\
n(\%) \\
{[1 \mathrm{C} 95 \%]}\end{array}$ & $\begin{array}{l}\text { Sudeste } \\
\mathrm{n}(\%) \\
{[\mathrm{IC} 95 \%]}\end{array}$ & $\begin{array}{c}\text { Sul } \\
\text { n (\%) } \\
{[\text { IC95\%] }}\end{array}$ & $\begin{array}{c}\text { Centro-Oeste } \\
\mathrm{n}(\%) \\
{[\mathrm{IC} 95 \%]}\end{array}$ & $\begin{array}{c}\text { Brasil } \\
\text { n (\%) } \\
{[\text { IC95\%] }}\end{array}$ \\
\hline \multicolumn{7}{|l|}{ Gênero * } \\
\hline Masculino & $\begin{array}{c}780(20,9) \\
{[19,6-22,2]}\end{array}$ & $\begin{array}{l}3.465(16,1) \\
{[15,6-16,6]}\end{array}$ & $\begin{array}{l}5.922(23,3) \\
{[22,8-23,8]}\end{array}$ & $\begin{array}{c}3.431(33,1) \\
{[32,2-34]}\end{array}$ & $\begin{array}{l}1.002(23,1) \\
{[21,8-24,4]}\end{array}$ & $\begin{array}{c}14.600(22,3) \\
{[22-22,6]}\end{array}$ \\
\hline Feminino & $\begin{array}{l}2.948(79,1) \\
{[77,8-80,4]}\end{array}$ & $\begin{array}{c}18.091(83,9) \\
{[83,4-84,4]}\end{array}$ & $\begin{array}{c}19.484(76,7) \\
{[76,2-77,2]}\end{array}$ & $\begin{array}{c}6.933(66,9) \\
{[66-67,8]}\end{array}$ & $\begin{array}{l}3.335(76,9) \\
{[75,6-78,2]}\end{array}$ & $\begin{array}{c}50.791(77,7) \\
{[77,4-78]}\end{array}$ \\
\hline $\begin{array}{l}\text { Idade (média } \\
\text { em anos) * }\end{array}$ & $\begin{array}{c}39,5 \\
{[39-40]}\end{array}$ & $\begin{array}{c}40,5 \\
{[40,3-40,7]}\end{array}$ & $\begin{array}{c}46,8 \\
{[46,6-47,1]}\end{array}$ & $\begin{array}{c}45,2 \\
{[44,9-45,5]}\end{array}$ & $\begin{array}{c}46,1 \\
{[45,6-46,7]}\end{array}$ & $\begin{array}{c}49,3 \\
{[49,1-49,5]}\end{array}$ \\
\hline $\begin{array}{c}\text { Renda } \\
\text { mensal da } \\
\text { família }(R \$) \text { * }\end{array}$ & $\begin{array}{c}1.178,6 \\
{[1064,4-1292,8]}\end{array}$ & $\begin{array}{c}1.000,1 \\
{[943-1057,2]}\end{array}$ & $\begin{array}{c}1.746,1 \\
{[1663,2-1829]}\end{array}$ & $\begin{array}{c}2.448,3 \\
{[2265,3-2631,4]}\end{array}$ & $\begin{array}{c}1.379,7 \\
{[1238,9-1520,5]}\end{array}$ & $\begin{array}{c}1.163,1 \\
{[1159,4-1166,7}\end{array}$ \\
\hline \multicolumn{7}{|l|}{ Raça/cor ** } \\
\hline Branca & $\begin{array}{c}605(16,3) \\
{[15,1-17,5]}\end{array}$ & $\begin{array}{c}4.984(23,4) \\
{[22,8-24]}\end{array}$ & $\begin{array}{c}10.282(40,8) \\
{[40,2-41,4]}\end{array}$ & $\begin{array}{l}7.694(74,7) \\
{[73,9-75,6]}\end{array}$ & $\begin{array}{l}1.599(37,1) \\
{[35,6-38,5]}\end{array}$ & $\begin{array}{c}25.164(38,8) \\
{[38,5-39,2]}\end{array}$ \\
\hline Preta & $\begin{array}{l}404(10,9) \\
{[9,9-11,9]}\end{array}$ & $\begin{array}{c}2.873(13,5) \\
\quad[13-14]\end{array}$ & $\begin{array}{c}3.532(14) \\
{[13,6-14,4]}\end{array}$ & $\begin{array}{c}674(6,5) \\
{[6,1-7]}\end{array}$ & $\begin{array}{c}483(11,2) \\
{[10,3-12,1]}\end{array}$ & $\begin{array}{c}7.966(12,3) \\
{[12-12,5]}\end{array}$ \\
\hline Amarela & $\begin{array}{l}108(2,9) \\
{[2,4-3,5]}\end{array}$ & $\begin{array}{c}746(3,5) \\
{[3,3-3,8]}\end{array}$ & $\begin{array}{r}550(2,2) \\
{[2-2,4]}\end{array}$ & $\begin{array}{c}191(1,9) \\
{[1,6-2,1]}\end{array}$ & $\begin{array}{c}140(3,2) \\
{[2,7-3,8]}\end{array}$ & $\begin{array}{r}1.735(2,7) \\
{[2,6-2,8]}\end{array}$ \\
\hline Parda/mestiça & $\begin{array}{l}2.533(68,3) \\
{[66,9-69,8]}\end{array}$ & $\begin{array}{c}12.439(58,4) \\
{[57,8-59,1]}\end{array}$ & $\begin{array}{r}10.666(42,3) \\
{[41,7-42,9]}\end{array}$ & $\begin{array}{c}1.643(16) \\
{[15,3-16,7]}\end{array}$ & $\begin{array}{l}2.030(47,1) \\
{[45,6-48,6]}\end{array}$ & $\begin{array}{c}29.311(45,2) \\
{[44,9-45,6]}\end{array}$ \\
\hline Indígena & $\begin{array}{c}56(1,5) \\
{[1,1-1,9]}\end{array}$ & $\begin{array}{c}247(1,2) \\
{[1-1,3]}\end{array}$ & $\begin{array}{l}162(0,6) \\
{[0,5-0,7]}\end{array}$ & $\begin{array}{c}91(0,9) \\
{[0,7-1,1]}\end{array}$ & $\begin{array}{l}60(1,4) \\
{[1-1,7]}\end{array}$ & $\begin{array}{l}616(1) \\
{[0,9-1]}\end{array}$ \\
\hline
\end{tabular}


Tabela 1 - Distribuição das características demográficas (gênero, idade e raça/cor) e econômicas (renda), da população estudada. Brasil e regiões, 2012.

(conclusão)

\begin{tabular}{|c|c|c|c|c|c|c|}
\hline Variável & $\begin{array}{c}\text { Norte } \\
\text { n (\%) } \\
{[I C 95 \%]}\end{array}$ & $\begin{array}{c}\text { Nordeste } \\
\mathrm{n}(\%) \\
{[\mathrm{IC} 95 \%]}\end{array}$ & $\begin{array}{c}\text { Sudeste } \\
\text { n (\%) } \\
{[\text { IC95\%] }}\end{array}$ & $\begin{array}{c}\text { Sul } \\
n(\%) \\
{[I C 95 \%]}\end{array}$ & $\begin{array}{c}\text { Centro-Oeste } \\
\mathrm{n}(\%) \\
{[\mathrm{IC} 95 \%]}\end{array}$ & $\begin{array}{c}\text { Brasil } \\
\text { n (\%) } \\
{[\mathrm{IC} 95 \%]}\end{array}$ \\
\hline \multicolumn{7}{|c|}{ Recebe o dinheiro do Programa Bolsa Família (PBF) atualmente? } \\
\hline Sim & $\begin{array}{l}1.791(48,1) \\
{[46,5-49,7]}\end{array}$ & $\begin{array}{c}11.895 \\
(55,2) \\
{[54,6-55,9]}\end{array}$ & $\begin{array}{l}5.271(20,8) \\
{[20,3-21,3]}\end{array}$ & $\begin{array}{r}1.732(16,7) \\
{[16-17,5]}\end{array}$ & $\begin{array}{c}988(22,8) \\
{[21,6-24,1]}\end{array}$ & $\begin{array}{r}21.677(33,2) \\
{[32,8-33,6]}\end{array}$ \\
\hline Não & $\begin{array}{l}204(5,5) \\
{[4,7-6,2]}\end{array}$ & $\begin{array}{r}1.484(6,9) \\
{[6,6-7,2]}\end{array}$ & $\begin{array}{c}1.422(5,6) \\
{[5,3-5,9]}\end{array}$ & $\begin{array}{l}435(4,2) \\
{[3,8-4,6]}\end{array}$ & $\begin{array}{l}194(4,5) \\
{[3,9-5,1]}\end{array}$ & $\begin{array}{c}3.739(5,7) \\
{[5,5-5,9]}\end{array}$ \\
\hline $\begin{array}{l}\quad \text { Não é } \\
\text { cadastrada no } \\
\text { PBF }\end{array}$ & $\begin{array}{c}1.728(46,4) \\
{[44,8-48]}\end{array}$ & $\begin{array}{l}8.152(37,9) \\
{[37,2-38,5]}\end{array}$ & $\begin{array}{c}18.679(73,6) \\
{[73,1-74,2]}\end{array}$ & $\begin{array}{l}8.183(79,1) \\
{[78,3-79,8]}\end{array}$ & $\begin{array}{c}3.145(72,7) \\
{[71,4-74]}\end{array}$ & $\begin{array}{r}39.887(61,1) \\
{[60,7-61,5]}\end{array}$ \\
\hline
\end{tabular}

Fonte: Dados do módulo III - Avaliação dos usuários. PMAQ-AB 1ํ ciclo, 2012.

Nota: os resultados expressam a frequência e o percentual de participantes. IC95\%: intervalo de $95 \%$ de confiança

* número de usuários entrevistados $=65.391$

** usuários que não sabem/não responderam $=599$. Usuários que responderam quanto à raça/cor $=64.792$

Há predominância do gênero feminino no Brasil (77,7\%; $\left.\mathrm{IC}_{95 \%}=77,4-78\right)$, sobretudo na região Nordeste. Na amostra populacional da região Norte, concentrase a população mais jovem, com média de 39,5 ( $\left.\mathrm{IC}_{95 \%}=39-40\right)$ anos de idade. $\mathrm{A}$ raça/cor mais referida entre o total de entrevistados foi a parda/mestiça (45,2\%; $I_{95 \%}=44,9$ - 45,6), sobretudo na amostra da região Norte, mas para a região Sul, a raça/cor mais prevalente foi a branca $\left(74,7 \%\right.$; $\left.\mathrm{IC}_{95 \%}=73,9-75,6\right)$. Com renda mensal familiar média de $\mathrm{R} \$ 2.448,30$, a amostra da região Sul mostrou-se em situação econômica superior às demais regiões do país e da média nacional ( $R \$$ $1.163,10)$.

Quanto ao recebimento do incentivo financeiro do Programa Bolsa Família (PBF), a maioria dos entrevistados $\left(61,1 \% ; I_{95 \%}=60,7-61,5\right)$ não era cadastrada no Programa. Do percentual de participantes do estudo que referiram receber 0 benefício do PBF, $\left(33,2 \% ; I_{95 \%}=32,8\right.$ - 33,6), destaca-se a região Nordeste $(55,2$; $I_{95 \%}=54,6$ - 55,9) e Norte $\left(48,1 ; I_{95 \%}=46,5\right.$ - 49,7) com frequência mais expressiva de afirmativas.

Para $67,1 \%\left(\mathrm{IC}_{95 \%}=66,7-67,4\right)$ da amostra populacional do Brasil, a unidade de saúde (US) localiza-se próxima à residência, principalmente, para a região 
Sudeste com 69,7\% (IC $95 \%=69,1$ - 70,2) em relação à região Norte $\left(59,6 \%\right.$; $I C_{95 \%}=$ 58,1 - 61,2). A US funciona nos cinco dias da semana para a maior parte dos entrevistados (95,8\%; IC $\mathrm{C}_{95 \%}=95,6$ - 95,9) e, de modo geral, o horário de funcionamento da unidade atende às suas necessidades $\left(86,5 \% ; \mathrm{IC}_{95 \%}=86,3\right.$ $86,8)$. Padrão de resposta semelhante é observado ao analisar estas variáveis nas cinco macrorregiões do país. Ao serem questionados quanto à possibilidade de horários diferenciados, todos os usuários entrevistados identificaram o horário da tarde até às $18 \mathrm{~h}$ e o período da noite como importantes para facilitar o atendimento na UBS. Tratava-se de uma pergunta com mais de um padrão de resposta (tabela 2). 
Tabela 2 - Distribuição relativa da acessibilidade geográfica e organizacional da população estudada. Brasil e regiões, 2012*.

(continua)

\begin{tabular}{ccccccc}
\hline & Norte & Nordeste & Sudeste & Sul & Centro-Oeste & Brasil \\
Variável & $\mathrm{n}(\%)$ & $\mathrm{n}(\%)$ & $\mathrm{n}(\%)$ & $\mathrm{n}(\%)$ & $\mathrm{n}(\%)$ & $\mathrm{n}(\%)$ \\
& {$[\mathrm{IC9} \%]$} & {$[\mathrm{IC} 95 \%]$} & {$[\mathrm{IC} 95 \%]$} & {$[\mathrm{IC} 95 \%]$} & {$[\mathrm{IC} 95 \%]$} & {$[\mathrm{IC} 95 \%]$} \\
\hline \hline
\end{tabular}

\section{A Unidade de Saúde está localizada:}

\begin{tabular}{ccccccc}
$\begin{array}{c}\text { Próxima à } \\
\text { casa do } \\
\text { usuário }\end{array}$ & $2.220(59,6)$ & $14.215(66,1)$ & $17.671(69,7)$ & $6.816(65,9)$ & $2.861(66,1)$ & $43.783(67,1)$ \\
& {$[58,1-61,2]$} & {$[65,4-66,7]$} & {$[69,1-70,2]$} & {$[65-66,8]$} & {$[64,7-67,5]$} & {$[66,7-67,4]$} \\
$\begin{array}{c}\text { Distante da } \\
\text { casa do }\end{array}$ & $657(17,7)$ & $2.984(13,9)$ & $3.020(11,9)$ & $1.288(12,5)$ & $608(14)$ & $8.557(13,1)$ \\
$\quad$ usuário & {$[16,4-18,9]$} & {$[13,4-14,3]$} & {$[11,5-12,3]$} & {$[11,8-13,1]$} & {$[13-15,1]$} & {$[12,8-13,4]$} \\
\hline
\end{tabular}

A Unidade de Saúde funciona os cinco dias da semana

$\begin{array}{cccccc}3.429(95,3) & 19.340(92,7) & 24.368(97,8) & 9.802(97,1) & 4.056(96,4) & 60.995(95,8) \\ {[94,6-96]} & {[92,3-93]} & {[97,6-98]} & {[96,8-97,4]} & {[95,8-97]} & {[95,6-95,9]}\end{array}$

O horário de funcionamento da Unidade de Saúde atende às necessidades de saúde do usuário

$\begin{array}{llllll}3.051(83,3) & 18.221(85,3) & 22.118(87,8) & 8.933(86,9) & 3.720(86,9) & 56.043(86,5)\end{array}$

$[82,1-84,5] \quad[84,8-85,8] \quad[87,4-88,2] \quad[86,3-87,6] \quad[85,9-87,9] \quad[86,3-86,8]$

Para facilitar o atendimento, gostaria que a unidade de saúde atendesse:

$\begin{array}{ccccccc}\begin{array}{c}\text { Mais cedo pela } \\ \text { manhã }\end{array} & 1.068(28,7) & 6.467(30) & 2893(11,4) & 1.410(13,6) & 670(15,5) & 12.508(19,1) \\ & {[27,2-30,2]} & {[29,4-30,7]} & {[11-11,8]} & {[13-14,3]} & {[14,4-16,5]} & {[18,8-19,4]} \\ \begin{array}{c}\text { À tarde até às } \\ \text { 18h }\end{array} & 3.721(100) & 21.528(100) & 25.389(100) & 10.359(100) & 4.336(100) & 65.333(100) \\ & & & & & & \\ \text { À noite } & 3.721(100) & 21.528(100) & 25.389(100) & 10.359(100) & 4.336(100) & 65.333(100) \\ & & & & & & \\ & & & & & & \\ \text { Aos sábados } & 1.433(38,5) & 8.229(38,2) & 8.943(35,2) & 3.243(31,3) & 1.398(32,2) & 23.246(35,6) \\ & {[36,9-40,1]} & {[37,6-38,9]} & {[34,6-35,8]} & {[30,4-32,2]} & {[30,9-33,6]} & {[35,2-35,9]} \\ \text { No horário de } & 532(14,3) & 3.051(14,2) & 1.810(7,1) & 1.472(14,2) & 570(13,1) & 7.435(11,4) \\ \text { almoço } & {[13,2-15,4]} & {[13,7-14,6]} & {[6,8-7,4]} & {[13,5-14,9]} & {[12,1-14,2]} & {[11,1-11,6]} \\ & & & & & & \end{array}$


Tabela 2 - Distribuição relativa da acessibilidade geográfica e organizacional da população estudada. Brasil e regiões, 2012*.

conclusão)

\begin{tabular}{ccccccc}
\hline & Norte & Nordeste & Sudeste & Sul & Centro-Oeste & Brasil \\
Variável & $\mathrm{n}(\%)$ & $\mathrm{n}(\%)$ & $\mathrm{n}(\%)$ & $\mathrm{n}(\%)$ & $\mathrm{n}(\%)$ & $\mathrm{n}(\%)$ \\
& {$[\mathrm{IC} 95 \%]$} & {$[\mathrm{IC} 95 \%]$} & {$[\mathrm{IC} 95 \%]$} & {$[\mathrm{IC} 95 \%]$} & {$[\mathrm{IC} 95 \%]$} & {$[\mathrm{IC} 95 \%]$} \\
\hline \hline
\end{tabular}

O médico está presente na unidade de saúde ou em atividades no bairro durante todos os horários de funcionamento da unidade de saúde

$\begin{array}{lccccc}2.106(59,3) & 12.344(60,4) & 16.770(69,7) & 7.270(75,1) & 2.896(69,9) & 41.386(66,9) \\ {[57,7-60,9]} & {[59,8-61,1]} & {[69,2-70,3]} & {[74,3-76]} & {[68,5-71,3]} & {[66,6-67,3]}\end{array}$

Existe a possibilidade de escolher a equipe que atende o usuário (médico, enfermeiro, ACS, outros)

$\begin{array}{cccccr}1.111(30,5) & 6.523(31,9) & 3.996(16,9) & 3.152(32,4) & 950(23) & 15.732(25,5) \\ {[29-32]} & {[31,2-32,5]} & {[16,4-17,3]} & {[31,5-33,3]} & {[21,7-24,3]} & {[25,2-25,9]}\end{array}$

Fonte: Dados do módulo III - Avaliação dos usuários. PMAQ-AB 1ำ ciclo, 2012.

Nota: os resultados expressam a frequência e o percentual de participantes. IC95\%: intervalo de $95 \%$ de confiança.

* Análise considerando os usuários que responderam afirmativamente às questões.

no total dos usuários entrevistados para cada questão=65.391.

Ainda na tabela 2, são apresentadas outras variáveis relativas às dimensões da acessibilidade funcional/organizacional. O profissional médico está presente na unidade de saúde ou em atividades no bairro durante todos os horários de funcionamento da unidade de saúde em 66,9\% (IC $95 \%=66,6$ - 67,3), principalmente, na região Sul para $75,1 \%\left(\mathrm{IC}_{95 \%}=74,3\right.$ - 76) da população estudada, em comparação à região Norte, em que este percentual foi de 59,3\% ( $\mathrm{IC}_{95 \%}=57,7$ 60,9). Igualmente na amostra da região Sul, com 32,4\% (IC $95 \%=31,5-33,3)$ observou-se maior frequência de respostas quanto à possibilidade do usuário em escolher a equipe de saúde que o atende (médico, enfermeiro, agente comunitário de saúde ou outros), em comparação com as demais regiões.

Para marcar consultas na unidade de saúde, 30,6\% $\left(\mathrm{IC}_{95 \%}=30,2-30,9\right)$ dos usuários entrevistados referiu precisar ir à unidade e para pegar a ficha de atendimento seria necessária a formação de fila antes da unidade de saúde abrir. Os usuários residentes nas regiões Sudeste $\left(38,3 \%\right.$; $I_{95 \%}=37,7$ - 38,9) e Centro-Oeste $\left(37,8 \% ; I_{95 \%}=36,4-39,3\right)$ podem marcar atendimento a qualquer hora. Nas demais regiões, com maior destaque para a região Sul $(40,9 \%$; IC $95 \%=40-41,9)$, é necessário formar fila antes da unidade de saúde abrir para que o usuário possa pegar a ficha de atendimento (tabela 3). 
Tabela 3 - Distribuição relativa da acessibilidade organizacional em relação à população estudada, quanto à marcação de consultas na unidade de saúde. Brasil e regiões, 2012*.

\begin{tabular}{|c|c|c|c|c|c|c|}
\hline Variável & $\begin{array}{c}\text { Norte } \\
\mathrm{n}(\%) \\
{[\mathrm{IC} 95 \%]}\end{array}$ & $\begin{array}{c}\text { Nordeste } \\
\text { n (\%) } \\
{[\text { IC95\%] }}\end{array}$ & $\begin{array}{l}\text { Sudeste } \\
\text { n (\%) } \\
\text { [IC95\%] }\end{array}$ & $\begin{array}{c}\text { Sul } \\
\text { n (\%) } \\
{[\text { IC95\%] }}\end{array}$ & $\begin{array}{c}\text { Centro-Oeste } \\
\text { n (\%) } \\
{[\text { IC95\%] }}\end{array}$ & $\begin{array}{c}\text { Brasil } \\
\mathrm{n}(\%) \\
{[\mathrm{IC} 95 \%]}\end{array}$ \\
\hline
\end{tabular}

Como ocorre a marcação da consulta na sua Unidade de Saúde?

\begin{tabular}{|c|c|c|c|c|c|c|}
\hline $\begin{array}{l}\text { Consulta marcada } \\
\text { pelo telefone. }\end{array}$ & $\begin{array}{c}24(0,6) \\
{[0,4-0,9]}\end{array}$ & $\begin{array}{c}90(0,4) \\
{[0,3-0,5]}\end{array}$ & $\begin{array}{c}497(2) \\
{[1,8-2,1]}\end{array}$ & $\begin{array}{l}696(6,7) \\
{[6,2-7,2]}\end{array}$ & $\begin{array}{l}157(3,6) \\
{[3,1-4,2]}\end{array}$ & $\begin{array}{r}1.464(2,2) \\
{[2,1-2,4]}\end{array}$ \\
\hline $\begin{array}{l}\text { Usuário vai à } \\
\text { unidade e marca o } \\
\text { atendimento a } \\
\text { qualquer hora. }\end{array}$ & $\begin{array}{c}732(19,6) \\
{[18,4-20,9]}\end{array}$ & $\begin{array}{c}3.566(16,6) \\
{[16,1-17]}\end{array}$ & $\begin{array}{l}9.716(38,3) \\
{[37,7-38,9]}\end{array}$ & $\begin{array}{l}2.670(25,8) \\
{[24,9-26,6]}\end{array}$ & $\begin{array}{l}1.641(37,8) \\
{[36,4-39,3]}\end{array}$ & $\begin{array}{c}1.8325(28) \\
{[27,7-28,4]}\end{array}$ \\
\hline $\begin{array}{l}\text { Usuário vai à } \\
\text { unidade, mas tem }\end{array}$ & $\begin{array}{l}1.041(27,9) \\
{[26,5-29,4]}\end{array}$ & $\begin{array}{l}6.294(29,2) \\
{[28,6-29,8]}\end{array}$ & $\begin{array}{l}5.099(20,1) \\
{[19,6-20,6]}\end{array}$ & $\begin{array}{c}2.162(20,9) \\
{[20,1-21, .7]}\end{array}$ & $\begin{array}{c}718(16,6) \\
{[15,5-17,7]}\end{array}$ & $\begin{array}{r}15.314(23,4) \\
{[23,1-23,8]}\end{array}$ \\
\hline
\end{tabular}

Usuário vai à unidade e para pegar ficha, é necessário fazer fila antes da unidade de saúde $1.076(28,9) \quad 8.178(38)$ $[27,4-30,3] \quad[37,3-38,6]$ $5.206(20,5) \quad 4.241(40,9) \quad 1.283(29,6)$ $19.984(30,6)$ abrir.

O ACS marca a consulta.

Outro

Fonte: Dados do módulo III - Avaliação dos usuários. PMAQ-AB 1ํㅜㄷㅣo, 2012.

* número de usuários entrevistados $=65.353$ (99,94\% da população estudada). IC95\%: intervalo de $95 \%$ de confiança

Na tabela 04, é possível observar que a população ao apresentar um problema de saúde que considera como urgência, busca os serviços de saúde $\left(63,3 \% ; I C_{95 \%}=62,9-63,6\right)$. Desses entrevistados que buscaram os diversos 
serviços de saúde, 65,3\% (IC $95 \%=64,8$ - 65,8) procuraram a US de referência para o seu atendimento. Aos que referiram não ter procurado a US em situações consideradas como urgências, os principais motivos apresentados foram: a US encontrar-se fechada no momento da urgência $\left(35,4 \%\right.$; $I_{95 \%}=34,6$ - 36,2) ou ainda por este serviço não atender urgências $\left(31,8 \%\right.$; $\mathrm{IC}_{95 \%}=31$ - 32,6).

Tabela 4 - Distribuição relativa da acessibilidade organizacional em relação à população estudada, quanto ao acolhimento à demanda espontânea. Brasil e regiões, 2012

(continua)

\begin{tabular}{ccccccc}
\hline \multirow{3}{*}{ Variável } & Norte & Nordeste & Sudeste & Sul & Centro-Oeste & Brasil \\
& $n(\%)$ & $n(\%)$ & $n(\%)$ & $n(\%)$ & $n(\%)$ & $n(\%)$ \\
& {$[$ IC95\%] } & {$[$ IC95\%] } & {$[$ IC95\%] } & {$[$ IC95\%] } & {$[$ IC95\%] } & {$[$ IC95\%] } \\
\hline \hline
\end{tabular}

O usuário procurou atendimento quando apresentou problema de saúde que considerou uma urgência*:

\begin{tabular}{|c|c|c|c|c|c|c|}
\hline Sim & $\begin{array}{c}2.411(65) \\
{[63,5-66,5]}\end{array}$ & $\begin{array}{c}12.652(58,9) \\
{[58,2-59,5]}\end{array}$ & $\begin{array}{c}16.145(63,8) \\
{[63,2-64,4]}\end{array}$ & $\begin{array}{l}7.365(71,3) \\
{[70,4-72,2]}\end{array}$ & $\begin{array}{l}2.645(61,2) \\
{[59,8-62,7]}\end{array}$ & $\begin{array}{c}41.218(63,3) \\
{[62,9-63,6]}\end{array}$ \\
\hline Não & $\begin{array}{c}460(12,4) \\
{[11,3-13,5]}\end{array}$ & $\begin{array}{c}1.756(8,2) \\
{[7,8-8,5]}\end{array}$ & $\begin{array}{r}2.236(8,8) \\
{[8,5-9,2]}\end{array}$ & $\begin{array}{l}547(5,3) \\
{[4,9-5,7]}\end{array}$ & $\begin{array}{c}497(11,5) \\
{[10,6-12,5]}\end{array}$ & $\begin{array}{c}5.496(8,4) \\
{[8,2-8,6]}\end{array}$ \\
\hline $\begin{array}{l}\text { Não teve } \\
\text { problema de } \\
\text { urgência }\end{array}$ & $\begin{array}{l}839(22,6) \\
{[21,3-24]}\end{array}$ & $\begin{array}{c}7.081(33) \\
{[32,3-33,6]}\end{array}$ & $\begin{array}{l}6.930(27,4) \\
{[26,8-27,9]}\end{array}$ & $\begin{array}{l}2.420(23,4) \\
{[22,6-24,2]}\end{array}$ & $\begin{array}{l}1.177(27,3) \\
{[25,9-28,6]}\end{array}$ & $\begin{array}{c}18.447(28,3) \\
{[28-28,7]}\end{array}$ \\
\hline \multicolumn{7}{|c|}{$\begin{array}{l}\text { Procurou atendimento nesta unidade de saúde quando apresentou problema que considerou urgência } \\
\text { A* }\end{array}$} \\
\hline Sim & $\begin{array}{l}1.407(58,4) \\
{[56,4-60,3]}\end{array}$ & $\begin{array}{l}8.024(63,4) \\
{[62,6-64,3]}\end{array}$ & $\begin{array}{l}10.864(67,3) \\
{[66,6-68]}\end{array}$ & $\begin{array}{l}5.157(70) \\
{[69-71,1]}\end{array}$ & $\begin{array}{l}1.463(55,3) \\
{[53,4-57,2]}\end{array}$ & $\begin{array}{c}26.915(65,3) \\
{[64,8-65,8]}\end{array}$ \\
\hline Não & $1.004(41,64)$ & $4.628(36,6)$ & $5.281(32,7)$ & $2.208(30)$ & $1.182(44,7)$ & $14.303(34,7)$ \\
\hline
\end{tabular}

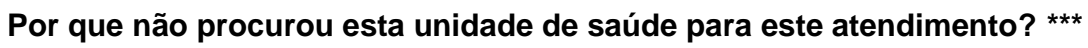

$\begin{array}{lcccccc}\begin{array}{l}\text { Por que precisa } \\ \text { chegar cedo }\end{array} & 13(1,3) & 50(1,1) & 49(0,9) & 33(1,5) & 16(1,4) & 161(1,1) \\ & {[0,6-2]} & {[0,8-1,4]} & {[0,7-1,2]} & {[1-2]} & {[0,7-2]} & {[1-1,3]} \\ \begin{array}{l}\text { Por que precisa } \\ \text { pegar ficha }\end{array} & 18(1,8) & 91(2) & 60(1,1) & 86(3,9) & 12(1) & 267(1,9) \\ & {[1-2,6]} & {[1,6-2,4]} & {[0,9-1,4]} & {[3,1-4,7]} & {[0,4-1,6]} & {[1,6-2,1]} \\ \begin{array}{l}\text { Por que não } \\ \text { atende sem }\end{array} & 49(4,9) & 164(3,5) & 294(5,6) & 109(4,9) & 42(3,6) & 658(4,6) \\ \begin{array}{l}\text { consulta } \\ \text { marcada }\end{array} & {[3,5-6,2]} & {[3-4,1]} & {[5-6,2]} & {[4-5,8]} & {[2,5-4,6]} & {[4,3-4,9]} \\ & & & & & \\ \begin{array}{l}\text { Por que não } \\ \text { tem profissional } \\ \text { na unidade }\end{array} & 71(7,1) & 549(11.9) & 385(7,3) & 170(7,7) & 76(6,4) & 1.251(8,7) \\ & {[5,5-8,7]} & {[10,9-12,8]} & {[6,6-8]} & {[6,6-8,8]} & {[5-7,8]} & {[8,3-9,2]} \\ \begin{array}{l}\text { Por que não } \\ \text { atende } \\ \text { urgência }\end{array} & 533(53,1) & 1.446(31,3) & 1.824(34,6) & 361(16,3) & 383(32,4) & 4.547(31,8) \\ & {[50-56,2]} & {[29,9-32,6]} & {[33,3-35,8]} & {[14,8-17,9]} & {[29,7-35,1]} & {[31-32,6]}\end{array}$


Tabela 4 - Distribuição relativa da acessibilidade organizacional em relação à população estudada, quanto ao acolhimento à demanda espontânea. Brasil e regiões, 2012

(conclusão)

\begin{tabular}{ccccccc}
\hline Variável & $\begin{array}{c}\text { Norte } \\
\mathrm{n}(\%) \\
{[\mathrm{IC} 95 \%]}\end{array}$ & $\begin{array}{c}\text { Nordeste } \\
\mathrm{n}(\%) \\
{[\mathrm{IC} 95 \%]}\end{array}$ & $\begin{array}{c}\text { Sudeste } \\
\mathrm{n}(\%) \\
{[\mathrm{IC} 95 \%]}\end{array}$ & $\begin{array}{c}\text { Sul } \\
\mathrm{n}(\%) \\
{[\mathrm{IC} 95 \%]}\end{array}$ & $\begin{array}{c}\text { Centro-Oeste } \\
\mathrm{n}(\%) \\
{[\mathrm{IC} 95 \%]}\end{array}$ & $\begin{array}{c}\text { Brasil } \\
\mathrm{n}(\%) \\
{[\mathrm{IC} 95 \%]}\end{array}$ \\
\hline \hline
\end{tabular}

Por que não procurou esta unidade de saúde para este atendimento? ***

\begin{tabular}{|c|c|c|c|c|c|c|}
\hline $\begin{array}{l}\text { Por que a } \\
\text { unidade estava } \\
\text { fechada no } \\
\text { momento da }\end{array}$ & $\begin{array}{c}209(21,1) \\
{[18,6-23,6]}\end{array}$ & $\begin{array}{c}1.584(34,6) \\
{[33,2-36]}\end{array}$ & $\begin{array}{c}1.659(31,7) \\
{[30,5-33]}\end{array}$ & $\begin{array}{l}1.096(50,4) \\
{[48,3-52,5]}\end{array}$ & $\begin{array}{c}454(38,9) \\
{[36,2-41,7]}\end{array}$ & $\begin{array}{l}5.002(35,4) \\
{[34,6-36,2]}\end{array}$ \\
\hline Outros & $\begin{array}{c}111(11,1) \\
{[9,1-13]}\end{array}$ & $\begin{array}{l}743(16,1) \\
{[15-17,1]}\end{array}$ & $\begin{array}{c}1.008(19,1) \\
{[18-20,2]}\end{array}$ & $\begin{array}{c}353(16) \\
{[14,5-17,5]}\end{array}$ & $\begin{array}{l}199(16,8) \\
{[14,7-19]}\end{array}$ & $\begin{array}{l}2.414(16,9) \\
{[16,3-17,5}\end{array}$ \\
\hline
\end{tabular}

Fonte: Dados do módulo III - Avaliação dos usuários. PMAQ-AB 1ํㅜㄷㅇ, 2012.

* número de usuários entrevistados = 65.161 (99,64\% da população total estudada). IC95\%: intervalo de 95\% de confiança.

** número de usuários entrevistados (responderam "sim" à pergunta: procurou atendimento quando apresentou problema de saúde que considerou uma urgência): 41.218 (63\% da população total estudada).

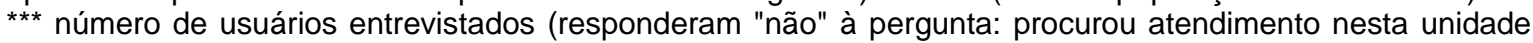
de saúde quando apresentou problema que considerou urgência): 14.303 (34,7\% da população que procurou atendimento em algum serviço de saúde, quando apresentou uma situação que considerou urgência). 


\section{DISCUSSÃO}

Por se tratar de um estudo descritivo, os seus resultados devem ser interpretados considerando-se os aspectos metodológicos do estudo, bem como suas limitações. Dentre essas podemos citar o desenho, de corte transversal, e a amostragem de conveniência - quatro usuários por unidade, em municípios que formalizaram a adesão e contratualização ao programa. Todavia pela abrangência e homogeneidade metodológica do estudo, os resultados possibilitam a percepção quanto aos obstáculos e avanços relacionados às dimensões da acessibilidade na $A B$ no Brasil, bem como contribui para apontar algumas questões relacionadas às desigualdades regionais no acesso.

Neste estudo verificou-se que a população feminina utiliza mais os serviços da $A B$ do que os homens. Resultados semelhantes têm sido encontrados em outros estudos $^{13-14}$. Isto se justifica pela percepção e perfil de necessidades de saúde entre os gêneros além das ofertas disponíveis, sobretudo nas unidades básicas de saúde, estarem muitas vezes relacionadas ao período gravídico e puerperal. As mulheres buscam mais os serviços de saúde para exames de rotina ou para cuidado preventivo, enquanto os homens buscam mais o cuidado curativo ${ }^{15}$, recorrendo aos serviços de saúde, quando não consegue exercer o seu papel de trabalhador ou a partir de intercorrências graves.

Quanto à idade, a maioria dos entrevistados tinha, em média, 39,5 anos de idade e renda média de $\mathrm{R} \$ 1.163,10$ reais, sendo a população da região nordeste a que apresentou a menor renda $(\mathrm{R} \$ 1.000,10)$.

Observou-se ainda que os entrevistados em sua maioria, não recebiam o benefício do Programa Bolsa Família (PBF), o que demonstra que não é somente a população mais pobre que utiliza os serviços de $A B$, embora as regiões nordeste e norte concentrem o maior percentual de beneficiários do PBF. Contudo é preciso destacar que a maioria dos municípios que realizaram a adesão ao primeiro ciclo do PMAQ-AB configurava-se proporcionalmente como de grande porte populacional e também com maiores Índices de Desenvolvimento Humano (IDH), sobretudo na região sul do Brasil. 
Quanto à dimensão da acessibilidade geográfica verificou-se que percentual importante dos entrevistados não considerou a distância entre a residência e a unidade de saúde como um obstáculo. Contudo, as regiões norte e nordeste apresentaram maiores frequências de menção à distância, enquanto barreira de acesso, em relação às demais regiões. Além da desigualdade econômica, identificada em todas as regiões brasileiras, sendo mais presente nessas duas regiões, têm-se também como fatores que influenciam na acessibilidade, o isolamento geográfico, a grande dimensão territorial com dificuldades de transporte, onde a região norte, por exemplo, possui $30 \%$ da população vivendo em meio rural, e apresenta maior dificuldade de utilizar os serviços de saúde, inclusive da Atenção Básica e onde, muitas vezes, os serviços concentram-se geograficamente nas capitais ou em municípios com maior porte populacional ${ }^{16-17}$.

Por ser a Atenção Básica o primeiro nível de contato dos indivíduos, da família e da comunidade com o sistema nacional de saúde, pelo qual os cuidados de saúde são levados o mais proximamente possível aos lugares onde pessoas vivem e trabalham ${ }^{18}$, a escassez ou mesmo ausência de unidades básicas de saúde nessas regiões comprometem a garantia da saúde como direito constitucional para a população desses territórios e refletem em indicadores de morbimortalidade mais críticos, em comparação às demais regiões do país ${ }^{19-22}$.

Considerando os diversos fatores ambientais, estruturais, econômicos, políticos, culturais e organizacionais ${ }^{23-24}$ que obstaculizam a acessibilidade dos usuários aos serviços de saúde, dentre eles as diversas barreiras geográficas (sejam estas naturais, comuns a algumas populações, a exemplo das ribeirinhas, ou de dimensionamento e planejamento da gestão, como construção de unidades de saúde distantes da vida cotidiana da população) é notório que estas permanecem se configurando como importantes problemas para a população e, portanto, um desafio a ser considerado nas políticas públicas.

Embora a amostra populacional, em sua grande maioria afirmasse que os horários de funcionamento da unidade atendia às suas necessidades, todos os entrevistados gostariam, para facilitar o atendimento, que a unidade de saúde abrisse à tarde, após as $18 \mathrm{~h}$ e à noite. Este achado assemelha-se ao encontrado em outros estudos, onde os entrevistados referiam que os horários após as 18h 
facilitariam o acesso da população trabalhadora ou de necessidades que surgem quando a unidade usualmente já se encontra fechada ${ }^{25-26}$.

Neste estudo observou-se também dificuldade do acesso da população ao profissional médico durante todos os horários de funcionamento da unidade de saúde, sobretudo nas regiões norte e nordeste, o que é também identificado em outros estudos realizados para dimensionar a força de trabalho do médico no Brasil, constatando lacunas importantes, sobretudo nessas duas regiões (regiões Norte e Nordeste, com $8 \%$ e $28 \%$ da população do país, que concentravam no mesmo período, $4,3 \%$ e $18,2 \%$ dos médicos, respectivamente, enquanto o Sudeste, com $42 \%$ da população concentrava $60 \%$ dos médicos) $)^{27}$.

A dificuldade de acesso ao profissional médico, especialmente nas regiões mais distantes ou nas áreas rurais e no interior dos municípios foi evidenciada pela Organização Mundial da Saúde $(\mathrm{OMS})^{28}$ e também pelo Conselho Federal de Medicina, onde no Brasil, a relação de médicos com registro ativo no conselho profissional era de 1,9 médicos por habitantes, tendo a região norte e sudeste 0,98 e 2,61 médicos por habitantes, respectivamente ${ }^{29}$.

A partir da carência de médicos, o governo brasileiro toma a decisão política de instituir o Programa Mais Médicos. Este apresenta como escopo a alocação de médicos brasileiros e estrangeiros em municípios selecionados, a expansão da oferta de cursos de medicina e vagas de Residência Médica, e na mudança dos currículos dos cursos de graduação, com vistas a diminuir as desigualdades no acesso à Atenção Básica ${ }^{30}$.

Embora reconhecendo a escassez de médicos no Brasil, sobretudo nas regiões norte e nordeste, e da importância e necessidade desse profissional compondo a equipe de saúde, é preciso romper com o paradigma estabelecido nos serviços e na sociedade, quanto à atenção à saúde centrada no médico, nos procedimentos e na medicalização dos problemas, onde os usuários direcionam a um profissional a responsabilidade pela sua saúde ${ }^{31-32}$. Além disso, o tempo de espera para o agendamento das consultas, não consideradas de urgência tende a ser demorado, com superlotação para o atendimento médico e pouco agendamento 
para o profissional enfermeiro, por exemplo, como demonstra estudo realizado em Florianópolis-SC, em 47 centros de saúde ${ }^{33}$.

Na maioria das vezes, esse modelo é pouco resolutivo, hierárquico do ponto de vista relacional e de baixa autonomia e responsabilização por parte dos usuários. Assim, é fundamental que seja fomentado um novo modelo de atenção, que considere o trabalho interdisciplinar, a clínica ampliada e os saberes dos diversos profissionais e do usuário, o protagonismo dos usuários e o cuidado compartilhado.

Além da carência do profissional médico, outro achado no estudo se relaciona com a impossibilidade de escolha da equipe de saúde que atende aos usuários. $\mathrm{Na}$ população estudada, 96,8\% das equipes se configuravam como eSF.

Pela Política Nacional de Atenção Básica, a eSF responsabiliza-se por uma determinada população adstrita e geograficamente delimitada, de modo a garantir o cuidado longitudinal, utilizando o enfoque do território, que tende a produzir um cuidado mais próximo e contínuo da população, além de permitir identificar e analisar as características e problemas de saúde da população, bem como a avaliação do impacto das ações de saúde ${ }^{34}$. Pessoa et $\mathrm{al}^{35}$, consideram o território como um híbrido entre sociedade e natureza, entre política, economia e cultura, e entre materialidade e "idealidade", numa complexa interação tempo-espaço.

Não há dúvidas quanto à importância da territorialização, adscrição e vinculação dos usuários a uma equipe de saúde. No entanto, em experiências internacionais, que consideram as questões relativas à vinculação dos usuários com os serviços existentes no território, existe a possibilidade dos usuários escolherem a equipe de saúde, podendo utilizar outros critérios como a proximidade do trabalho ${ }^{36-}$ 42. Acredita-se que liberdade de escolha das equipes ou dos profissionais pelos usuários contribui para maior adesão ao tratamento e aos cuidados. Todavia, os países onde foram encontradas essas experiências possuem cobertura de APS acima de $90 \%$ e um número de população por equipe de saúde inferior a 2.000 pessoas. No Brasil, em 2012 e 2016, contava-se respectivamente com 54,8\% e $60,9 \%$ de cobertura da eSF e um número superior de população adscrita por equipe de saúde. Ademais, é necessário destacar que, no Brasil, ainda existem muitas 
unidades básicas em conformidade com o modelo tradicional ${ }^{36}$ pouco alinhado com os atributos essenciais da APS, sobretudo quanto à acessibilidade social e cultural.

A forma de agendamento de consultas mais referida pelos usuários que participaram do estudo foi através de ficha, mas onde é necessário aos usuários formar fila antes da unidade de saúde abrir (30,6\%), sendo esse padrão de resposta mais observado nos usuários da região sul do país (40,9\%). Esta forma de agendar 0 atendimento na unidade, também percebida em outros estudos ${ }^{43-44}$, além de ser considerada como importante barreira ao acesso aos serviços de saúde, é também limitada, uma vez que considera apenas as queixas e percepções das desordens biomédicas, não valorizando as demais necessidades da população e que porventura a levaram a buscar apoio junto à equipe de saúde da UBS.

Além disso, há a tendência para a cultura da medicalização do sofrimento humano, e consequente incessante busca da população por cuidados médicos, que por sua vez, não conseguem absorver as demandas da população, gerando insatisfação entre os usuários e profissionais de saúde ${ }^{45}$.

Uma forma de organizar o acesso aos serviços da UBS, e principalmente às consultas, seria o acolhimento, através de uma escuta atenta aos problemas de saúde, buscando dar respostas às necessidades do usuário, estabelecendo vínculos de cuidado e confiança, baseados em abordagens centradas na pessoa e não na doença. Essa prática pode auxiliar na definição da Atenção Básica como o lócus de cuidado preferencial no sistema de saúde, superando a negativa da atenção pela ausência das fichas.

Por fim, o estudo revelou que para percentual importante dos entrevistados, sobretudo das regiões centro-oeste e norte, a $A B$ não é o serviço de procura da população em situações consideradas como urgência, seja por que a unidade não atendia urgência ou por que a mesma encontrava-se fechada, sendo esse tipo de achado percebido em estudo anteriormente realizado ${ }^{46}$.

A Política Nacional da AB (PNAB) prevê no processo de trabalho das equipes, dentre outras ações, a realização do acolhimento com escuta qualificada, classificação de risco, avaliação de necessidade de saúde e análise de vulnerabilidade, bem como disposição de uma assistência resolutiva à demanda 
espontânea e o primeiro atendimento às urgências, contudo este estudo mostra que estes ainda são grandes desafios.

A $A B$ possui enquanto função nas RAS, dentre outras, ser resolutiva, coordenar o cuidado e ordenar as redes ${ }^{47}$. A associação da AB como porta prioritária para as redes concerne na sua capacidade de ser o local onde se apresentam os problemas de saúde, bem como de diagnóstico e tratamento, seja em situações agudas ou crônicas.

Igualmente, a Politica Nacional de Atenção às Urgências através da constituição da Rede de Urgência e Emergência (RUE) prevê enquanto objetivo atribuído à $A B$ o primeiro cuidado às urgências e emergências, em ambiente adequado, até a transferência ou encaminhamento a outros pontos de atenção, quando necessário.

Contudo, além do horário de funcionamento das unidades de saúde, que muitas vezes não permite o acesso dos usuários em situações de urgência ou de demanda não agendada, ainda é comum a percepção por parte dos profissionais e da população que a este nível de atenção deve ser responsável apenas por desenvolver ações de promoção e proteção da saúde e prevenção dos agravos, além de organizar-se para ações programadas do ciclo de vida (crianças, adolescentes, adultos e idosos), não estando, muitas vezes, disponível para a demanda espontânea da população.

Segundo estudo ecológico realizado em 1960, e reeditado com ampliação de amostra em $2001^{48}$, em sistemas de saúde com APS forte, é possível que a população tenha a maior parte das suas necessidades respondidas por esse nível de atenção, sendo poucos usuários encaminhados aos serviços especializados ou hospitalares.

Como a maior parte dos atendimentos de urgência são por condições crônicas que agudizaram, e tendo a AB maior capacidade de conhecer a história das pessoas do território, este seria um importante ponto de atenção que faz a integração e coordenação do cuidado com os demais pontos de atenção. No entanto, o que se observa na maioria dos serviços, ou em boa parte deles, é pouco acesso às queixas/sofrimentos das pessoas, levando-as a buscar atenção em 
serviços de pronto atendimento ou emergências hospitalares, gerando superlotação nos mesmos, com demandas que deveriam ser atendidas na Atenção Básica, deslegitimando-a socialmente ${ }^{49}$.

Em experiências internacionais ${ }^{50}$ é possível identificar a Atenção Primária como porta de entrada do sistema de saúde que busca que não haja nenhum tempo de espera, sendo os usuários atendidos no mesmo dia por algum profissional, ou em até 48 horas pelo médico da unidade de saúde.

Todavia, para a oferta de atenção às urgências e à demanda espontânea é importante que seja disponibilizado aos profissionais de saúde, estruturas físicas e ambiência adequada ao cuidado nas unidades de saúde, bem como insumos, equipamentos e medicamentos, sendo esses desafios ainda presentes no Brasil e que muitas vezes também levam ao encaminhamento dos usuários aos serviços hospitalares e de pronto atendimento.

Há também a percepção por parte dos gestores e trabalhadores que o número elevado de pessoas sob responsabilidade de uma equipe, em boa parte das regiões do Brasil, em comparação aos países que demonstram apresentar forte $\mathrm{APS}^{51}$, impossibilita a atenção integral, incluindo o acesso às urgências ${ }^{52}$.

Além disso, é fundamental que ocorra por parte dos trabalhadores e da gestão, a análise e o planejamento do processo de trabalho das equipes, a partir de indicadores e da avaliação dos usuários, a disponibilização de atualização e educação permanente, e ainda, fluxo de comunicação eficaz entre os profissionais dentro da rede de atenção, possibilitando o matriciamento e a coordenação do cuidado entre os diversos serviços. 


\section{CONSIDERAÇÕES FINAIS}

A acessibilidade em saúde na Atenção Básica, em suas duas dimensões, ainda é considerada como grande desafio para a implementação das políticas no Brasil, sobretudo se considerarmos as diversidades regionais. As barreiras geográficas ainda configuram-se como importantes obstáculos do acesso, desse modo, arranjos diferentes devem ser vislumbrados.

O acesso dificultado pela organização das ações dos profissionais e do serviço evidencia a necessidade de romper com as práticas de cuidado centradas no profissional médico, bem como no acesso a partir das fichas e filas e na restrição das consultas para as demandas baseadas nas ações programáticas. A partir de ofertas de saúde mais inclusivas, desde o horário de atendimento flexível às necessidades até a possibilidade de escolha da equipe de saúde por parte dos usuários, de modo a valorizar o vínculo, tende a produzir na Atenção Básica a indispensável legitimidade social, onde a população reconhece nesse ponto de atenção, um espaço de acesso e resolutividade.

O estudo possibilitou ainda conhecer a avaliação dos usuários quanto às dimensões da acessibilidade na Atenção Básica, de modo regionalizado, a partir dos dados do PMAQ-AB. Como o programa permite a avaliação singularizada, desde a equipe até a análise regional e nacional, espera-se que seja fomentado o estudo dos dados do PMAQ-AB, bem como o uso dos seus resultados, enquanto substrato para o planejamento das ações de saúde, pelas três instâncias de gestão do SUS, visando a qualidade e o fortalecimento da $A B$. 


\section{REFERÊNCIAS}

1. Ministério da Saúde (BR). Secretaria de Atenção à Saúde. Departamento de Atenção Básica. Política Nacional de Atenção Básica. Brasília: Ministério da Saúde; 2012.

2. Donabedian A. Aspects of medical care administration. Cambridge: Harvard University Press; 1973.

3. Starfield, B. Atenção Primária: equilíbrio entre necessidades de saúde, serviços e tecnologia. Brasília: UNESCO, Ministério da Saúde; 2002.

4. Travassos C, Viacava F, Pinheiro R, Brito A. Utilization of health care services in Brazil: gender, family characteristics, and social status. Rev. Pan. de Salud Pub., 2002; 11: 365-373.

5. Szwarcwald CL, Souza-Junior PR, Damacena GN. Socioeconomic inequalities in the use of outpatient services in Brazil according to health care need: evidence from the World Health Survey. BMC Health Services Research, 2010; 10:217.

6. Macinko J, Lima Costa MF. Access to, use of and satisfaction with health services among adults enrolled in Brazil's Family Health Strategy: evidence from the 2008 National Household Survey. Trop Med Int Health, 2012;17:36.

7. Macinko, J, Harris, MJ. Brazil's family health strategy-delivering communitybased primary care in a universal health system. New England Journal of Medicine, 2015; 372(23), 2177-2181.

8. Vasconi AS, Menezes, RA. Os sentidos do Acolhimento: um estudo sobre o acesso à atenção básica em saúde no Rio de Janeiro. Cad. Saúde Colet., 2014; Rio de Janeiro, 22 (4): 380-5.

9. Viegas APB, Carmo RF, Luz ZMP. Fatores que influenciam o acesso aos serviços de saúde na visão de profissionais e usuários de uma unidade básica de referência. Saúde Soc., 2015; 24(1): 100-112.

10.Finkler AL,Viera CS, Tacla MT, Toso BR. O acesso e a dificuldade na resolutividade do cuidado da criança na atenção primária à saúde. Acta Paul Enferm. 2014; 27 (6): 548-53.

11.Barbiani R. et al. A produção científica sobre acesso no âmbito do Sistema Único de Saúde do Brasil: avanços, limites e desafios. Saúde e Soc. 2014; 23(3): 855-868.

12. Ministério da Saúde (BR). Portaria n. 1.654, de 19 de julho de 2011 (BR). Institui, no âmbito do Sistema Único de Saúde, o Programa Nacional de Melhoria do Acesso e da Qualidade da Atenção Básica (PMAQ-AB) e o Incentivo Financeiro do PMAQ-AB, denominado Componente de Qualidade 
do Piso de Atenção Básica Variável - PAB Variável. Diário Oficial [da] República Federativa do Brasil, Brasília: 20 jul. 2011. n. 138, Seção I, p. 79.

13. Gomes R, Moreira MCN, Nascimento do EF, Rebello de LEFS, Couto MTSB. Os homens não vêm! Ausência e/ou invisibilidade masculina na atenção primária. Ciênc. saúde coletiva. 2011; 16(Suppl 1): 983-992.

14. Vieira KLD, Gomes VLO, Borba MR, Costa CFS. Atendimento da população masculina em unidade básica saúde da família: motivos para a (não) procura. Esc Anna Nery (impr.)2013; 17 (1):120 - 127.

15. Moura EC, et al. Atenção à saúde dos homens no âmbito da Estratégia Saúde da Família. Ciênc. \& Saúde Coletiva, 2014; 19(2):429-438.

16. Silva RR, Bacha CJC. Acessibilidade e aglomerações na Região Norte do Brasil sob o enfoque da nova geografia econômica. Nova Economia Belo Horizonte. 2014;24(1):169-190.

17. Escorel S. et al. O Programa de Saúde da Família e a construção de um novo modelo para a atenção básica no Brasil. Revista Panamericana de Salud Publica, Washington, 2007;21(2): 164-176.

18. Organização Mundial de Saúde (OMS). Conferência Internacional sobre Cuidados Primários de Saúde. Alma-Ata, URSS, 6-12 de setembro de 1978.

19. Viellas EF, Domingues RMSM, Dias MAB, Gama SGN, Theme-Filha MM, Costa JV, Bastos MH, Leal MC. Assistência pré-natal no Brasil. Cad. Saúde Pública. 2014; 30 (Supl.): S85-S100.

20.Bühler HF et al. Análise espacial de indicadores integrados determinantes da mortalidade por diarreia aguda em crianças menores de 1 ano em regiões geográficas. Ciênc. Saúde Coletiva. 2014; 19(10): 4131-4140.

21. Klafke $A$ et al. Mortalidade por complicações agudas do diabetes melito no Brasil, 2006-2010. Epidemiol. Serv. Saúde. 2014; 23(3):455-462.

22. Girianelli VR et al. Contrastes na mortalidade por câncer feminino. Rev Saúde Pública 2014;48(3):459-467.

23. Travassos C, Martins M. Uma revisão sobre os conceitos de acesso e utilização de serviços de saúde. Cad. Saúde Publica. 2004; 20(Supl. 2):190198.

24. Assis MMA, Jesus WLA. Acesso aos serviços de saúde: abordagens, conceitos, políticas e modelo de análise. Ciênc. \& Saúde Coletiva, 2012; 17(11):2865-2875.

25. Lima SAV, Silva MRF da, Carvalho EMF de, Pessoa EÂC, Brito ESV de, Braga JPR. Elementos que influenciam o acesso à atenção primária na 
perspectiva dos profissionais e dos usuários de uma rede de serviços de saúde do Recife. Physis. 2015;25(2): 635-656.

26. Campos FE, Machado MH, Girardi SN. A fixação de profissionais de saúde em regiões de necessidades. Divulg Saúde Debate. 2009;(44):13-24.

27. Organização Mundial da Saúde. Increasing access to health workers in remote and rural areas through improved retention: global policy recommendations. Genebra: World Wealth Organization; 2010.

28. Conselho Federal de Medicina. Demografia Médica no Brasil. São Paulo: Conselho Regional de Medicina do Estado de São Paulo: Conselho Federal de Medicina; 2013.

29. Organização Pan-Americana da Saúde. Nota da OPAS/OMS no Brasil sobre o Projeto Mais Médicos, 2015.

30. Seán Boyle: United Kingdom (England): Health system review. Health Systems in Transition, 2011; 13(1):1-486.

31. Coelho MO, Jorge M SB. Tecnologia das relações como dispositivo do atendimento humanizado na atenção básica à saúde na perspectiva do acesso, do acolhimento e do vínculo. Cienc Saúde Coletiva, 2009; 14(suppl 1):1523-1531.

32. Campos RTO, et al. Avaliação da qualidade do acesso na atenção primária de uma grande cidade brasileira na perspectiva dos usuários. Saúde em Debate, 2014; 38(sppl): 252-264.

33.Tesser CD, Norman AH. Repensando o acesso ao cuidado na Estratégia Saúde da Família. Saúde Soc. São Paulo,2014; 23(3):869-883.

34. Dias EC, Rigotto RM, Augusto LGS, Cancio J, Hoefe MGL. Saúde ambiental e saúde do trabalhador na atenção primária à saúde, no SUS: oportunidade e desafios. Cien Saude Colet. 2009; 14(6):2061-2070.

35.Pessoa VM, Rigotto RM, Teixeira ACA, Pinheiro TMM. As novas necessidades de saúde nos territórios dos sertanejos do baixo Vale do Jaguaribe-CE e os desafios à política pública de saúde. In: Rigotto RM, organizadora. Agrotóxicos, trabalho e saúde. 2011; Edições UFC:549-583.

36. Giovanella L, Stegmüller, K. Tendências de reformas da atenção primária à saúde em países europeus. J Manag Prim Health Care 2014; 5(1):101-113.

37. Marchildon GP. Canada: Health system review. Health Systems in Transition, 2013; 15(1): 1-179.

38. Barros P, Machado S, Simões J. Portugal: Health system review. Health Systems in Transition, 2011, 13(4):1-156. 
39.García-Armesto S, Abadía-Taira MB, Durán A, Hernández-Quevedo C, Bernal-Delgado E. Spain: Health system review. Health Systems in Transition, 2010, 12(4):1-295.

40. Ferré $F$, de Belvis AG, Valerio L, Longhi S, Lazzari A, Fattore G, Ricciardi W, Maresso A. Italy: Health System Review. Health Systems in Transition, 2014, 16(4):1-168.

41.BoyleS. United Kingdom (England): Health system review. Health Systems in Transition, 2011; 13(1):1-486.

42. Ringard Å, Sagan A, Sperre Saunes I, Lindahl AK. Norway: Health system review. Health Systems in Transition, 2013; 15(8): 1- 162.

43. Sarti TD, A marcação de consulta médica em uma unidade de saúde da família: uma etnografia a respeito dos conflitos entre usuários e profissionais de saúde. Rev. APS. 2014 jul/set; 17(3): 362 - 372.

44.Sousa FOS et al. Do normativo à realidade do Sistema Único de Saúde: revelando barreiras de acesso na rede de cuidados assistenciais. Ciência \& Saúde Coletiva, 19(4):1283-1293, 2014.

45.Norman AH, Tesser, CD. Acesso ao cuidado na Estratégia Saúde da Família: equilíbrio entre demanda espontânea e prevenção/promoção da saúde. Saúde Soc. São Paulo, v.24, n.1, p.165-179, 2015.

46. Carret MLV, Fassa ACG, Domingues MR. Inapropriate use of emergency services: a systematic review of prevalence and associated factors. Cad. Saúde Pública. 2009; 25 (1): 7-28.

47.Boerma, WGW, Dubois CA Mapeamento da Atenção Primária em toda a Europa. In: Saltmam, RB, Rico A, Boerma, WGW et al. Atenção Primária Conduzindo as Redes de Atenção à Saúde: reforma organizacional na atenção primária europeia [trad.]. 2010; Glasgow: Bell \&BainLtd.

48. Green L A. et al. The ecology of medical care revisited. New England Journal of Medicine, Waltham, 2001;344(26):2021-2025.

49. Oliveira LH, et al. Cidadãos peregrinos: os "usuários" do SUS e os significados de sua demanda a prontos-socorros e hospitais no contexto de um processo de reorientação do modelo assistencial. Ciência \& Saúde Coletiva, 2009;14(5): 1929- 1938.

50.Salisbury C, Banks J, Goodall S, Baxter H, Montgomery A, Pope, et al. Na evaluation of Advanced Acess in general practice: final report. Bristol: NHS, 2007.

51.Giovanella L. et al. Políticas e sistema de saúde no Brasil. Fiocruz, 2008. 
52. Soares SS, Lima LD, Castro, ALB. O papel da atenção básica no atendimento às urgências: um olhar sobre as políticas. J Manag Prim Health Care 2014;5(2):170-177. 


\section{ARTIGO 2: A AVALIAÇÃO DOS USUÁRIOS DA ATENÇÃO BÁSICA QUANTO À INTEGRALIDADE, À LONGITUDINALIDADE E À COORDENAÇÃO DO CUIDADO.}

THE EVALUATION OF USERS OF PRIMARY CARE AS TO THE INTEGRALITY, LONGITUDINALITY AND COORDINATION OF CARE.

\section{Autores:}

Daniela Cristina Moreira M. de Figueiredo ${ }^{1}$

Helena Eri Shimizu²

Walter Massa Ramalho ${ }^{3}$

${ }^{1}$ Mestranda em Saúde Coletiva pela Universidade de Brasília (UnB). Consultora Técnica do Departamento de Atenção Básica do Ministério da Saúde. Endereço: SQS 306, bloco K, apto 403. Brasília, Distrito Federal. CEP: 70353-110. Telefone: (61) 8109-8816. E-mail: dla.moreira@yahoo.com.br

${ }^{2}$ Doutora em Enfermagem pela Universidade de São Paulo. Professora Adjunta do Departamento de Saúde Coletiva (DSC) da Faculdade de Ciências da Saúde (FS) da Universidade de Brasília (UnB). Brasília, Distrito Federal.

Telefone: (61) 3072-115. E-mail: Shimizu@unb.br

${ }^{3}$ Doutor em Medicina Tropical pela Universidade de Brasília. Professor Adjunto da UnB - Faculdade de Ceilândia, curso Gestão em Saúde / Área de Epidemiologia. Endereço: QNN 14 Área Especial - Ceilândia Sul CEP: 72220-140. Brasília, Distrito Federal. E-mail: Walter.ramalho@gmail.com 


\title{
RESUMO
}

Este estudo teve como objetivo descrever a avaliação dos usuários da Atenção Básica no Brasil quanto aos atributos da integralidade, longitudinalidade e coordenação do cuidado. Trata-se de uma pesquisa com abordagem quantitativa, do tipo transversal de caráter descritivo e multicêntrico, por meio de dados secundários da avaliação externa do Programa Nacional de Melhoria do Acesso e da Qualidade da Atenção Básica, com a participação de 65.391 usuários. Os dados revelaram avanços quanto à expansão da Atenção Básica e à busca pela resolutividade, contudo, ainda, é preciso avançar em questões importantes voltadas à qualidade da Atenção Básica, como a oferta de cuidados centrados nas pessoas, o cuidado continuado do profissional de saúde produzido a partir do vínculo e da coordenação do cuidado.

Descritores: Atenção Primária à Saúde; Avaliação em saúde; Política de saúde.

\begin{abstract}
This study aimed to describe the evaluation of primary care users in Brazil, about the integrality longitudinality and coordination of care attributes. This is a research with a quantitative approach, a cross-sectional descriptive and multicenter, through secondary data the external evaluation of the National Programme for Improving Access and Quality of Primary Care, with the participation of 65,391 users. Data revealed advances in the expansion of primary care and the search for resolution, however, is still necessary to move forward on important issues facing quality of primary care, such as the provision of care focused on people, the continued care of the health professional produced from the bond and coordination of care.
\end{abstract}

Keywords: Primary Health Care; Health Evaluation; Health Policy. 


\section{INTRODUÇÃO}

Os sistemas de atenção à saúde baseados na Atenção Primária à Saúde (APS) estão relacionados com melhor qualidade da atenção e menores custos ${ }^{1-2}$. Além disso, a população assistida por sistemas com APS forte tem mais oportunidades de ter acesso aos cuidados preventivos apropriados, de relatar maior satisfação na atenção prestada e de produzir projetos terapêuticos mais eficientes e aplicáveis ${ }^{3}$.

Também foi observado que países com APS mais forte reduziram os anos potenciais de vida perdidos e que maiores taxas de médicos de família por população estavam associadas a melhores resultados sanitários em relação às populações mais pobres, permitindo, assim, aos autores perceber como benefícios da APS: acesso oportuno aos serviços necessários, qualidade no cuidado, atenção para a promoção à saúde e prevenção de doenças, gestão precoce dos problemas de saúde, qualificação dos encaminhamentos à atenção secundária e sua consequente redução, entre outros ${ }^{4}$.

No Brasil, principalmente a partir da implantação da Estratégia Saúde da Família, enquanto modelo de reorientação assistencial, garantiu-se aumento significativo da cobertura de Atenção Primária à população, ampliando e aperfeiçoando as ações de vigilância em saúde, que tem resultado na importante redução da morbidade e mortalidade, especialmente em relação aos agravos infectocontagiosos.

No entanto, com a mudança no perfil sociodemográfico, epidemiológico e nutricional do Brasil em algumas regiões, seguindo o padrão de países desenvolvidos, mas mantendo em algumas localidades o padrão de problemas de saúde e sociais de países subdesenvolvidos, torna-se ainda mais desafiante que as politicas e ações em saúde estejam voltadas às necessidades diversas da população.

Para isso, é fundamental o empenho constante da gestão, trabalhadores de saúde e sociedade, no sentido de tornar a $A B$ cada vez mais fortalecida e com legitimidade, garantindo além do acesso da população, através da cobertura, 
também a qualidade do cuidado e da atenção, através do vínculo, continuidade do cuidado, da integralidade da atenção, bem como contar com a avaliação da população que a utiliza, de modo a perceber se as ações e ofertas de saúde atendem às reais necessidades das pessoas.

Nessa lógica, a $A B$ deve ter capilaridade e estar próxima da vida das pessoas. Ademais, deve ser o contato preferencial dos usuários e o centro de comunicação com toda a Rede de Atenção à Saúde ${ }^{5}$.

$\mathrm{Na}$ perspectiva de buscar induzir mudanças na melhoria do acesso e da qualidade da $A B$, o Ministério da Saúde instituiu o Programa Nacional de Melhoria do Acesso e da Qualidade na Atenção Básica (PMAQ-AB), alinhado com os objetivos e desafios da Política Nacional de Atenção Básica (PNAB) e com a necessidade de fomentar processos de avaliação dos serviços de saúde. Dentre as suas etapas, o PMAQ-AB conta com a avaliação externa, que analisa questões relacionadas ao acesso e à qualidade da $A B$ nas equipes que decidem participar do Programa e conta, ainda, com um módulo específico de avaliação do usuário.

E nesse sentido, a existência de instrumentos de avaliação da percepção das pessoas que utilizam os serviços de saúde é fundamental para a análise e planejamento das ações em saúde, corroborando para fortalecer a participação da sociedade nas decisões tomadas pelo Estado no interesse geral, inserindo o cidadão e o usuário no centro do processo de avaliação ${ }^{7}$, proporcionando, assim, benefícios à população a partir de ações e projetos em saúde. Portanto, a opinião dos usuários quanto à qualidade da atenção é considerada de extrema relevância quando se busca avaliar e contribuir com a melhoria dos serviços de saúde ${ }^{8}$.

Nesse sentido, torna-se importante que sejam avaliadas as impressões dos usuários quanto à qualidade da atenção e aos atributos da APS, principalmente quanto às ações e ofertas de saúde baseadas nas necessidades da população, apreendidas a partir do estabelecimento de vínculos e da continuidade do cuidado entre os usuários dos serviços e os profissionais de saúde, bem como da interrelação entre a APS e os demais serviços da rede de atenção.

Nesse sentido, estudos de abrangência nacional, que permitam avaliar os atributos da integralidade, longitudinalidade e coordenação do cuidado, sob a ótica 
dos usuários, possibilitam que sejam produzidos conhecimento e estratégias/ações visando à melhoria do cuidado.

Com base na importância de avaliar os atributos supracitados, escolheu-se 0 PMAQ-AB, como instrumento de avaliação, pela sua abrangência nacional e regionalizada, que contribui para a percepção dos padrões de resposta considerando as especificidades locorregionais.

Assim, o presente estudo objetivou descrever a avaliação dos usuários que participaram do PMAQ-AB, no ano de 2012, com relação à qualidade da atenção, considerando a integralidade, a longitudinalidade e a coordenação do cuidado observando como as respostas se apresentam nas macrorregiões do país. 


\section{MÉTODO}

Trata-se de um estudo com abordagem quantitativa, do tipo transversal e de caráter descritivo, baseado na análise de dados secundários da etapa de avaliação externa do Programa de Melhoria do Acesso e da Qualidade na Atenção Básica (PMAQ-AB). Os dados foram coletados no ano de 2012 e estão disponíveis ao domínio público nacional.

Para a análise foram utilizados os dados do módulo III que estão relacionados à entrevista com usuários na Unidade Básica de Saúde (UBS) quanto a sua experiência na utilização dos serviços de saúde.

Como critérios de inclusão foram considerados no momento da entrevista com o usuário: usuários dos serviços de Atenção Básica no Brasil, maiores de 18 anos de idade, não ter passado pela consulta ou atendimento antes da entrevista, ter vínculo com a equipe de Saúde da Família (não sendo aplicado o questionário se aquele fosse o primeiro momento dele com a equipe) e ter realizado pelo menos um atendimento na unidade nos últimos doze meses.

No estudo participaram, ao todo, 65.391 usuários, vinculados às equipes de saúde de Atenção Básica, dos municípios brasileiros que aderiram ao PMAQ-AB de modo voluntário em seu primeiro ciclo. Isso corresponde a $53,9 \%$ do total das equipes de Atenção Básica existentes no país no ano de 2012.

O estudo seguiu as recomendações éticas na coleta dos dados com os entrevistados, respeitando os princípios da bioética e apresentando parecer favorável do Comitê de Ética em Pesquisa da Universidade Federal do Rio Grande do Sul (UFRGS).

Do total de variáveis presentes no instrumento da avaliação externa, módulo do usuário, foram selecionadas cinco variáveis referentes à caracterização sociodemográfica e econômica da população estudada (gênero, idade, raça/cor e renda) e variáveis que permitem observar a percepção dos usuários quanto às questões relacionadas à integralidade da atenção, à longitudinalidade e à coordenação do cuidado, totalizando na seleção de 12 variáveis. 
As descrições dos resultados basearam-se em comparações proporcionais das respostas das variáveis dos questionários, adotando-se como recorte as cinco regiões brasileiras. Os dados foram armazenados e organizados em uma planilha eletrônica do software Microsoft Office Excel 2010 para Windows®. Para os cálculos dos intervalos de confiança das proporções utilizou-se uma significância de 0,05. 


\section{RESULTADOS}

A população do estudo (tabela 1) revelou ser predominantemente feminina ( $\mathrm{n}$ : $50.791 ; 77,7 \%)$, com idade média de 49,3 anos de idade, referindo como raça/cor a parda/mestiça $(n=29.311 ; 45,2 \%)$ e renda familiar de 1,93 salários mínimos para o ano de $2012(\mathrm{R} \$ 1.163,1)$.

Tabela 1 - Distribuição das características demográficas (gênero, idade e raça/cor) e econômicas (renda) da população estudada. Brasil, 2012

\begin{tabular}{ccc}
\hline Variável & $\begin{array}{c}\text { Brasil } \\
\mathrm{n}(\%)\end{array}$ & IC 95\% \\
\hline Gênero* & $14.600(22,3)$ & $22-22,6$ \\
Masculino & $50.791(77,7)$ & $77,4-78$ \\
Feminino & 49,3 & $49,1-49,5$ \\
\hline Idade (média em anos) * & $1.163,1$ & $1159,4-1166,7$ \\
\hline Renda mensal da família (R\$) * & & \\
\hline Raça/cor ** & & $38,5-39,2$ \\
Branca & $25.164(38,8)$ & $12-12,5$ \\
Preta & $7.966(12,3)$ & $2,6-2,8$ \\
Amarela & $1.735(2,7)$ & $44,9-45,6$ \\
Parda/mestiça & $29.311(45,2)$ & $0,9-1$ \\
Indígena & $616(1)$ &
\end{tabular}

Nota: os resultados expressam a frequência e o percentual de participantes.

IC95\%: intervalo de 95\% de confiança

* número de usuários entrevistados $=65.391$

** usuários que não sabem/não responderam = 599. Usuários que responderam quanto à raça/cor $=64.792$

Quanto às variáveis referentes à qualidade da atenção prestada pelas equipes de Atenção Básica, a tabela 2 demonstra que para $73,1 \%$ da população estudada, a equipe busca resolver as suas necessidades/problemas na própria unidade de saúde, resultado que se apresentou de modo semelhante nas diversas regiões. 
Ainda observando a tabela 2, os usuários entrevistados referiram que os profissionais de saúde fazem sempre perguntas sobre outras necessidades de saúde além daquelas relacionadas com o motivo da consulta, em 49,6\% na amostra nacional. As regiões com os extremos nas frequências para essa variável foram as regiões Sudeste (n: $13.765 ; 54.9 \%)$ e Norte (n: $1.512 ; 41.4 \%)$.

Para $50,7 \%$ dos entrevistados, durante as consultas, os profissionais da equipe de saúde da $A B$ sempre sugerem soluções adequadas as suas realidades, destacando-se novamente as regiões Sudeste ( $n: 13.371 ; 54.4)$ e Norte ( $n: 1.357$; $38.5 \%$ ) com maiores e menores frequências, respectivamente, para esta afirmação (tabela 2).

Tabela 2 - Distribuição das respostas dos usuários da Atenção Básica, participantes do $P M A Q-A B$, quanto às variáveis relacionadas à integralidade da atenção. Brasil e regiões, 2012

(continua)

\begin{tabular}{ccccccc}
\hline \multirow{3}{*}{ Variável } & Norte & Nordeste & Sudeste & Sul & Centro-Oeste & Brasil \\
& $n(\%)$ & $n(\%)$ & $n(\%)$ & $n(\%)$ & $n(\%)$ & $n(\%)$ \\
& {$[I C 95 \%]$} & {$[I C 95 \%]$} & {$[I C 95 \%]$} & {$[I C 95 \%]$} & {$[$ IC95\%] } & {$[$ IC95\%] } \\
\hline
\end{tabular}

Quando é atendido (a) nesta unidade de saúde, o (a) senhor (a) acha que a equipe busca resolver suas necessidades/problemas na própria unidade de saúde? *

\begin{tabular}{lcccccc}
\hline & & & & & \\
Sim & $2.556(69.3)$ & $15.077(70.5)$ & $\begin{array}{c}18.783 \\
(74.5)\end{array}$ & $7.914(77)$ & $3.061(71.2)$ & $47.391(73.1)$ \\
& {$[67.8-70.8]$} & {$[69.9-71.1]$} & {$[74-75.1]$} & {$[76.2-77.9]$} & {$[69.8-72.5]$} & {$[72.7-73.4]$} \\
Sim, & $786(21.3)$ & $4.947(23.1)$ & 4.714 & $1.945(18.9)$ & $908(21.1)$ & $13.300(20.5)$ \\
$\begin{array}{l}\text { algumas } \\
\text { vezes }\end{array}$ & {$[20-22.6]$} & {$[22.6-23.7]$} & $\begin{array}{c}(18.7) \\
{[18.2-19.2]}\end{array}$ & {$[18.2-19.7]$} & {$[19.9-22.3]$} & {$[20.2-20.8]$} \\
& & & & & & \\
Nunca & $346(9.4)$ & $1.371(6.4)$ & $1.702(6.8)$ & $414(4)$ & $333(7.7)$ & $4.166(6.4)$ \\
& {$[8.4-10.3]$} & {$[6.1-6.7]$} & {$[6.4-7.1]$} & {$[3.6-4.4]$} & {$[6.9-8.5]$} & {$[6.2-6.6]$} \\
& & & & & & \\
\hline
\end{tabular}

Os profissionais de saúde fazem perguntas sobre outras necessidades de saúde que o(a) senhor(a) tem ou possa ter além daquelas relacionadas com o motivo da consulta? **

\begin{tabular}{lcccccc}
\hline Sempre & $1.512(41.4)$ & $9.970(47)$ & $13.765(54.9)$ & $4.743(46.5)$ & $1.964(46.3)$ & $31.954(49.6)$ \\
& {$[39.8-43]$} & {$[46.3-47.6]$} & {$[54.3-55.6]$} & {$[45.5-47.5]$} & {$[44.8-47.8]$} & {$[49.2-50]$} \\
& & & & & & \\
$\mathrm{Na}$ & $591(16.2)$ & $3.489(16.4)$ & $3.855(15.4)$ & $1.715(16.8)$ & $651(15.3)$ & $10.301(16)$ \\
maioria & {$[15-17.4]$} & {$[15.9-16.9]$} & {$[14.9-15.8]$} & {$[16.1-17.5]$} & {$[14.3-16.4]$} & {$[15.7-16.3]$} \\
das vezes & {$[15.9 .16$}
\end{tabular}


Tabela 2 - Distribuição das respostas dos usuários da Atenção Básica, participantes do $P M A Q-A B$, quanto às variáveis relacionadas à integralidade da atenção. Brasil e regiões, 2012

(conclusão)

\begin{tabular}{ccccccc}
\hline & & & & & & \\
Vorte & Nordeste & Sudeste & Sul & Centro-Oeste & Brasil \\
& $\mathrm{n}(\%)$ & $\mathrm{n}(\%)$ & $\mathrm{n}(\%)$ & $\mathrm{n}(\%)$ & $\mathrm{n}(\%)$ & $\mathrm{n}(\%)$ \\
& {$[\mathrm{IC} 95 \%]$} & {$[\mathrm{IC} \% 5 \%]$} & {$[\mathrm{IC} 95 \%]$} & {$[\mathrm{IC} 95 \%]$} & {$[\mathrm{IC} 95 \%]$} & {$[\mathrm{IC} 95 \%]$} \\
\hline
\end{tabular}

Os profissionais de saúde fazem perguntas sobre outras necessidades de saúde que o(a) senhor(a) tem ou possa ter além daquelas relacionadas com o motivo da consulta? **

\begin{tabular}{lcccccc}
\hline $\begin{array}{l}\text { Quase } \\
\text { nunca }\end{array}$ & $331(9.1)$ & $1.647(7.8)$ & $1.656(6.6)$ & $815(8)$ & $317(7.5)$ & $4.766(7.4)$ \\
& {$[8.1-10]$} & {$[7.4-8.1]$} & {$[6.3-6.9]$} & {$[7.5-8.5]$} & {$[6.7-8.3]$} & {$[7.2-7.6]$} \\
& & & & & & \\
Nunca & $1.215(33.3)$ & $6.123(28.8)$ & $5.777(23.1)$ & $2.929(28.7)$ & $1.313(30.9)$ & $17.357(27)$ \\
& {$[31.8-34.8]$} & {$[28.2-29.5]$} & {$[22.5-23.6]$} & {$[27.8-29.6]$} & {$[29.5-32.3]$} & {$[26.6-27.3]$}
\end{tabular}

Na opinião do(a) senhor(a), durante as consultas, os profissionais desta equipe sugerem soluções adequadas a sua realidade? ${ }^{\star \star *}$

\begin{tabular}{|c|c|c|c|c|c|c|}
\hline Sempre & $\begin{array}{l}1.357(38.5) \\
{[36.9-40.1]}\end{array}$ & $\begin{array}{l}9.925(47.6) \\
{[46.9-48.3]}\end{array}$ & $\begin{array}{c}13.371(54.4) \\
{[53.8-55.1]}\end{array}$ & $\begin{array}{l}5.324(53.1) \\
{[52.1-54.1]}\end{array}$ & $\begin{array}{l}2.033(48.3) \\
{[46.8-49.8]}\end{array}$ & $\begin{array}{c}32.010(50.7) \\
{[50.3-51.1]}\end{array}$ \\
\hline $\begin{array}{l}\text { Na maioria } \\
\text { das vezes }\end{array}$ & $\begin{array}{l}762(21.6) \\
{[20.3-23]}\end{array}$ & $\begin{array}{c}3.967(19) \\
{[18.5-19.6]}\end{array}$ & $\begin{array}{l}4.407(17.9) \\
{[17.5-18.4]}\end{array}$ & $\begin{array}{c}2.004(20) \\
{[19.2-20.8]}\end{array}$ & $\begin{array}{c}658(15.6) \\
{[14.5-16.7]}\end{array}$ & $\begin{array}{c}11.798(18.7) \\
{[18.4-19]}\end{array}$ \\
\hline $\begin{array}{l}\text { Quase } \\
\text { nunca }\end{array}$ & $\begin{array}{c}337(9.6) \\
{[8.6-10.5]}\end{array}$ & $\begin{array}{c}1.566(7.5) \\
{[7.2-7.9]}\end{array}$ & $\begin{array}{l}1.856(7.6) \\
{[7.2-7.9]}\end{array}$ & $\begin{array}{c}674(6.7) \\
{[6.2-7.2]}\end{array}$ & $\begin{array}{l}276(6.6) \\
{[5.8-7.3]}\end{array}$ & $\begin{array}{c}4.709(7.5) \\
{[7.3-7.7]}\end{array}$ \\
\hline Nunca & $\begin{array}{l}1.067(30.3) \\
{[28.8-31.8]}\end{array}$ & $\begin{array}{l}5.391(25.9) \\
{[25.3-26.5]}\end{array}$ & $\begin{array}{l}4.929(20.1) \\
{[19.6-20.6]}\end{array}$ & $\begin{array}{l}2.020(20.2) \\
{[19.4-20.9]}\end{array}$ & $\begin{array}{l}1.240(29.5) \\
{[28.1-30.9]}\end{array}$ & $\begin{array}{c}14.647(23.2) \\
{[22.9-23.5]}\end{array}$ \\
\hline $\begin{array}{l}\text { Nota: os res } \\
\text { IC95\%: inte } \\
{ }^{*} n=64.85 \\
{ }^{\star \star} n=64.37 \\
{ }^{* \star *} n=63.1\end{array}$ & $\begin{array}{l}\text { ados expres } \\
\text { lo de } 95 \% \text { de } \\
99,2 \% \text { do tot } \\
(98,5 \% \text { do to } \\
(96,6 \% \text { do to }\end{array}$ & $\begin{array}{l}\text { a frequência } \\
\text { ffiança. } \\
\text { usuários en } \\
\text { e usuários er } \\
\text { e usuários e }\end{array}$ & $\begin{array}{l}\text { percentual o } \\
\text { stados) } \\
\text { istados) } \\
\text { istados) }\end{array}$ & rticipantes. & & \\
\hline
\end{tabular}

Quando questionados sobre o atendimento ser realizado sempre pelo mesmo profissional na unidade de saúde (tabela 3), 64,4\% dos entrevistados revelaram que sempre são atendidos pelo mesmo médico e $57,8 \%$ pelo mesmo enfermeiro. $\mathrm{Na}$ análise regional, a região Sudeste apresentou maior percentual em relação ao profissional médico ser o mesmo que sempre atende ao usuário ( $\mathrm{n}: 17.369 ; 68.5 \%$ ), em comparação com a região Norte ( $n$ : $1.894 ; 50.8 \%)$. Contudo, quanto ao profissional enfermeiro, a diferença entre os maiores e menores percentuais foram observados nas regiões Nordeste (n: 15.254; 70.8\%) e Sul (n: 4.051; 39.1\%). 
A tabela 3 apresenta também os resultados da avaliação dos usuários quanto à pergunta se os profissionais de saúde recordam do que aconteceu com o usuário nas últimas consultas. Para $50,3 \%$ desses, os profissionais sempre se recordam do que aconteceu nas ultimas consultas, prevalecendo o maior percentual dessa resposta na região Sul do país ( $n=13.200 ; 54.3 \%$ ) e o menor percentual na região Norte $(n=1.600 ; 44.2 \%)$.

Tabela 3 - Distribuição das respostas dos usuários da Atenção Básica, participantes do $P M A Q-A B$, quanto às variáveis relacionadas à longitudinalidade do cuidado. Brasil e regiões, 2012

(continua)

\begin{tabular}{ccccccc}
\hline \multirow{5}{*}{ Variável } & Norte & Nordeste & Sudeste & Sul & Centro-Oeste & Brasil \\
& $\mathrm{n}(\%)$ & $\mathrm{n}(\%)$ & $\mathrm{n}(\%)$ & $\mathrm{n}(\%)$ & $\mathrm{n}(\%)$ & $\mathrm{n}(\%)$ \\
& {$[\mathrm{IC95 \% ]}$} & {$[\mathrm{IC95 \% ]}$} & {$[\mathrm{IC} 95 \%]$} & {$[\mathrm{IC95 \% ]}$} & {$[\mathrm{IC95 \% ]}$} & {$[\mathrm{IC} 95 \%]$} \\
\hline \hline
\end{tabular}

Nessa unidade o (a) senhor (a) é atendido pelo mesmo médico *:

\begin{tabular}{lcccccc}
\hline & $1.894(50.8)$ & $14.051(65.2)$ & $17.369(68.5)$ & $6.026(58.2)$ & $2.725(62.9)$ & $42.065(64.4)$ \\
Sempre & {$[49.2-52.5]$} & {$[64.6-65.9]$} & {$[67.9-69]$} & {$[57.3-59.2]$} & {$[61.5-64.4]$} & {$[64-64.8]$} \\
& & & & & & \\
Na maioria & $813(21.8)$ & $3.605(16.7)$ & $4.004(15.8)$ & $2.361(22.8)$ & $910(21)$ & $11.693(17.9)$ \\
das vezes & {$[20.5-23.2]$} & {$[16.2-17.2]$} & {$[15.3-16.2]$} & {$[22-23.6]$} & {$[19.8-22.2]$} & {$[17.6-18.2]$} \\
Quase & $629(16.9)$ & $2.251(10.5)$ & $2.810(11.1)$ & $1.341(13)$ & $507(11.7)$ & $7.538(11.5)$ \\
nunca & {$[15.7-18.1]$} & {$[10-10.9]$} & {$[10.7-11.5]$} & {$[12.3-13.6]$} & {$[10.7-12.7]$} & {$[11.3-11.8]$} \\
& & & & & & \\
Nunca & $371(10)$ & $1.209(5.6)$ & $1.045(4.1)$ & $576(5.6)$ & $161(3.7)$ & $3.362(5.1)$ \\
& {$[9-10.9]$} & {$[5.3-5.9]$} & {$[3.9-4.4]$} & {$[5.1-6]$} & {$[3.2-4.3]$} & {$[5-5.3]$} \\
\hline
\end{tabular}

\begin{tabular}{|c|c|c|c|c|c|c|}
\hline Sempre & $\begin{array}{c}2.072(55.6) \\
{[54-57.2]}\end{array}$ & $\begin{array}{c}15.254(70.8) \\
{[70.2-71.4]}\end{array}$ & $\begin{array}{c}13.838(54.6) \\
{[53.9-55.2]}\end{array}$ & $\begin{array}{l}4.051(39.1) \\
{[38.2-40.1]}\end{array}$ & $\begin{array}{l}2.560(59.1) \\
{[57.6-60.6]}\end{array}$ & $\begin{array}{c}37.775(57.8) \\
{[57.5-58.2]}\end{array}$ \\
\hline $\begin{array}{l}\text { Na maioria } \\
\text { das vezes }\end{array}$ & $\begin{array}{c}693(18.6) \\
{[17.4-19.9]}\end{array}$ & $\begin{array}{l}2.386(11.1) \\
{[10.7-11.5]}\end{array}$ & $\begin{array}{l}4.612(18.2) \\
{[17.7-18.7]}\end{array}$ & $\begin{array}{l}2.996(28.9) \\
{[28.1-29.8]}\end{array}$ & $\begin{array}{c}767(17.7) \\
{[16.6-18.8]}\end{array}$ & $\begin{array}{c}11.454(17.5) \\
{[17.2-17.8]}\end{array}$ \\
\hline $\begin{array}{l}\text { Quase } \\
\text { nunca }\end{array}$ & $\begin{array}{l}408(11) \\
{[10-12]}\end{array}$ & $\begin{array}{l}1.049(4.9) \\
{[4.6-5.2]}\end{array}$ & $\begin{array}{l}3.732(14.7) \\
{[14.3-15.1]}\end{array}$ & $\begin{array}{l}1.901(18.4) \\
{[17.6-19.1]}\end{array}$ & $\begin{array}{c}389(9) \\
{[8.1-9.8]}\end{array}$ & $\begin{array}{l}7.479(11.5) \\
{[11.2-11.7]}\end{array}$ \\
\hline Nunca & $\begin{array}{c}454(12.2) \\
{[11.1-13.2]}\end{array}$ & $\begin{array}{l}1.400(6.5) \\
{[6.2-6.8]}\end{array}$ & $\begin{array}{c}1.723(6.8) \\
{[6.5-7.1]}\end{array}$ & $\begin{array}{c}925(8.9) \\
{[8.4-9.5]}\end{array}$ & $\begin{array}{l}322(7.4) \\
{[6.7-8.2]}\end{array}$ & $\begin{array}{c}4.824(7.4) \\
{[7.2-7.6]}\end{array}$ \\
\hline
\end{tabular}


Tabela 3 - Distribuição das respostas dos usuários da Atenção Básica, participantes do $P M A Q-A B$ quanto às variáveis relacionadas à longitudinalidade do cuidado. Brasil e regiões, 2012

(conclusão)

\begin{tabular}{ccccccc}
\hline & Norte & Nordeste & Sudeste & Sul & Centro-Oeste & Brasil \\
Variável & $\mathrm{n}(\%)$ & $\mathrm{n}(\%)$ & $\mathrm{n}(\%)$ & $\mathrm{n}(\%)$ & $\mathrm{n}(\%)$ & $\mathrm{n}(\%)$ \\
& {$[\mathrm{IC} 95 \%]$} & {$[\mathrm{IC} 95 \%]$} & {$[\mathrm{IC} 95 \%]$} & {$[\mathrm{IC} 95 \%]$} & {$[\mathrm{IC} 95 \%]$} & {$[\mathrm{IC} 95 \%]$} \\
\hline \hline
\end{tabular}

Os profissionais lembram-se do que aconteceu nas últimas consultas do (a) senhor (a)? ${ }^{\star \star \star}$

\begin{tabular}{lcccccc}
\hline Sim & $1.600(44.2)$ & $9.781(47.5)$ & $13.200(54.3)$ & $4.949(50.2)$ & $1.918(46.4)$ & $31.448(50.3)$ \\
& {$[42.6-45.8]$} & {$[46.8-48.2]$} & {$[53.7-54.9]$} & {$[49.2-51.2]$} & {$[44.9-47.9]$} & {$[49.9-50.7]$} \\
Sim, & & & & & & \\
algumas & $518(14.3)$ & $3.535(17.2)$ & $3.869(15.9)$ & $1.836(18.6)$ & $596(14.4)$ & $10.354(16.6)$ \\
vezes & {$[13.2-15.5]$} & {$[16.7-17.7]$} & {$[15.5-16.4]$} & {$[17.9-19.4]$} & {$[13.3-15.5]$} & {$[16.3-16.9]$} \\
& & & & & & \\
Não & $1.501(41.5)$ & $7.270(35.3)$ & $7.230(29.8)$ & $3.073(31.2)$ & $1.622(39.2)$ & $20.696(33.1)$ \\
& {$[39.9-43.1]$} & {$[34.7-36]$} & {$[29.2-30.3]$} & {$[30.3-32.1]$} & {$[37.7-40.7]$} & {$[32.7-33.5]$} \\
\hline \hline
\end{tabular}

Nota: os resultados expressam a frequência e o percentual de participantes.

IC95\%: intervalo de $95 \%$ de confiança.

${ }^{*} \mathrm{n}=64.658(98,9 \%$ do total de usuários entrevistados)

** $\mathrm{n}=61.532(94,1 \%$ do total de usuários entrevistados)

${ }^{* * *} \mathrm{n}=62.498$ (95,6\% do total de usuários entrevistados)

Por fim, as variáveis apresentadas na tabela 4 apresentam as respostas quanto ao retorno do usuário após ser encaminhado para profissionais fora da unidade de saúde e quanto ao acesso ao resultado dos exames que chegam à UBS. Do total de entrevistados, 29,2\% afirmam que após serem atendidos por outros profissionais fora da $A B$, a equipe conversou sobre o atendimento realizado no outro serviço. Quanto à facilidade para saber dos resultados dos exames, $65,8 \%$ dos entrevistados referiram de modo afirmativo a esta pergunta, sendo as regiões Sul $(n=7.393 ; 71.5 \%)$ e Sudeste $(n=18.095 ; 71.4 \%)$ onde esta frequência foi a mais presente, e Nordeste $(n=12.399 ; 57.7 \%)$ e Norte $(n=2.200 ; 59.1 \%)$ as regiões onde a frequência foi menos expressiva. 
Tabela 4 - Distribuição das respostas dos usuários da Atenção Básica, participantes do $P M A Q-A B$, quanto às variáveis relacionadas à coordenação do cuidado. Brasil e regiões, 2012

\begin{tabular}{|c|c|c|c|c|c|c|}
\hline Variável & $\begin{array}{c}\text { Norte } \\
\mathrm{n}(\%) \\
{[\mathrm{IC} 95 \%]}\end{array}$ & $\begin{array}{c}\text { Nordeste } \\
n(\%) \\
{[I C 95 \%]}\end{array}$ & $\begin{array}{l}\text { Sudeste } \\
\mathrm{n}(\%) \\
{[1 \mathrm{C} 95 \%]}\end{array}$ & $\begin{array}{c}\text { Sul } \\
\mathrm{n}(\%) \\
{[\mathrm{IC} 95 \%]}\end{array}$ & $\begin{array}{c}\text { Centro-Oeste } \\
n(\%) \\
{[I C 95 \%]}\end{array}$ & $\begin{array}{l}\text { Brasil } \\
\text { n (\%) } \\
{[\text { IC95\%] }}\end{array}$ \\
\hline \multicolumn{7}{|c|}{$\begin{array}{l}\text { Depois que o (a) senhor (a) foi atendido (a) por outros profissionais fora desta unidade de saúde, a } \\
\text { equipe conversou com o (a) senhor (a) sobre este atendimento? }{ }^{*}\end{array}$} \\
\hline Sim & $\begin{array}{l}796(21.4) \\
{[20.1-22.7]}\end{array}$ & $\begin{array}{l}5.560(25.9) \\
{[25.3-26.4]}\end{array}$ & $\begin{array}{l}8.341(32.9) \\
{[32.3-33.5]}\end{array}$ & $\begin{array}{l}3.375(32.7) \\
{[31.8-33.6]}\end{array}$ & $\begin{array}{l}1.006(23.3) \\
{[22-24.5]}\end{array}$ & $\begin{array}{l}19.078(29.2) \\
{[28.9-29.6]}\end{array}$ \\
\hline $\begin{array}{l}\text { Sim, } \\
\text { algumas } \\
\text { vezes }\end{array}$ & $\begin{array}{l}310(8.3) \\
{[7.4-9.2]}\end{array}$ & $\begin{array}{l}1.983(9.2) \\
{[8.8-9.6]}\end{array}$ & $\begin{array}{c}2.380(9.4) \\
{[9-9.7]}\end{array}$ & $\begin{array}{l}1.208(11.7) \\
{[11.1-12.3]}\end{array}$ & $\begin{array}{c}318(7.4) \\
{[6.6-8.1]}\end{array}$ & $\begin{array}{c}6.199(9.5) \\
{[9.3-9.7]}\end{array}$ \\
\hline Nunca & $\begin{array}{l}1.309(35.2) \\
{[33.6-36.7]}\end{array}$ & $\begin{array}{l}7.202(33.5) \\
{[32.9-34.1]}\end{array}$ & $\begin{array}{l}8.645(34.1) \\
{[33.5-34.7]}\end{array}$ & $\begin{array}{l}3.578(34.6) \\
{[33.7-35.5]}\end{array}$ & $\begin{array}{l}1.432(33.1) \\
{[31.7-34.5]}\end{array}$ & $\begin{array}{l}22.166(34) \\
{[33.6-34.3]}\end{array}$ \\
\hline
\end{tabular}

O (a) senhor (a) encontra facilidade para saber dos resultados dos seus exames que chegam nesta unidade de saúde? **

\begin{tabular}{|c|c|c|c|c|c|c|}
\hline Sim & $\begin{array}{l}2.200(59.1) \\
{[57.5-60.7]}\end{array}$ & $\begin{array}{c}12.399(57.7) \\
{[57-58.3]}\end{array}$ & $\begin{array}{c}18.095(71.4) \\
{[70.8-71.9]}\end{array}$ & $\begin{array}{l}7.393(71.5) \\
{[70.7-72.4]}\end{array}$ & $\begin{array}{c}2.852(66) \\
{[64.5-67.4]}\end{array}$ & $\begin{array}{c}42.939(65.8) \\
{[65.5-66.2]}\end{array}$ \\
\hline $\begin{array}{l}\text { Sim, } \\
\text { algumas } \\
\text { vezes }\end{array}$ & $\begin{array}{c}576(15.5) \\
{[14.3-16.6]}\end{array}$ & $\begin{array}{c}3.988(18.6) \\
{[18-19.1]}\end{array}$ & $\begin{array}{c}3.400(13.4) \\
{[13-13.8]}\end{array}$ & $\begin{array}{c}1.449(14) \\
{[13.4-14.7]}\end{array}$ & $\begin{array}{c}643(14.9) \\
{[13.8-15.9]}\end{array}$ & $\begin{array}{c}10.056(15.4) \\
{[15.1-15.7]}\end{array}$ \\
\hline Nunca & $\begin{array}{l}946(25.4) \\
{[24-26.8]}\end{array}$ & $\begin{array}{l}5.111(23.8) \\
{[23.2-24.3]}\end{array}$ & $\begin{array}{l}3.857(15.2) \\
{[14.8-15.7]}\end{array}$ & $\begin{array}{l}1.491(14.4) \\
{[13.8-15.1]}\end{array}$ & $\begin{array}{l}829(19.2) \\
{[18-20.3]}\end{array}$ & $\begin{array}{c}12.234(18.8) \\
{[18.5-19.1]}\end{array}$ \\
\hline
\end{tabular}

Nota: os resultados expressam a frequência e o percentual de participantes.

IC95\%: intervalo de $95 \%$ de confiança.

${ }^{*} \mathrm{n}=47.443$ (72,6\% do total de usuários entrevistados). Não sabe/Não respondeu $=17.792$ (27,2\% do total de usuários entrevistados).

${ }^{* *} n=65.229(99,8 \%$ do total de usuários entrevistados) 


\section{DISCUSSÃO}

A população prevalente no estudo é do sexo feminino, com idade média de 49,3 anos de idade, tendência observada em outros estudos que demonstram a procura mais expressiva das mulheres aos serviços de saúde, principalmente para as ofertas de atenção materno-infantil, mesmo sendo o público masculino de maior taxa de mortalidade em todas as idades e que apresentam doenças, mais severas, em comparação às mulheres ${ }^{9-10}$. Esse perfil de busca aos serviços da APS deve-se, muitas vezes, às ofertas programáticas e menos às demandas espontâneas.

Quanto à raça/cor e à renda, os usuários declararam ser pardos e possuir renda média de $R \$ 1 \cdot 163,10$. Estudo anterior ${ }^{10}$ revelou que além do sexo feminino, as mulheres brancas apresentam maior chance de utilizar os serviços de saúde, em comparação às não brancas. Além disso, as pessoas empregadas no setor formal da economia, donas de casa de famílias com chefes do sexo masculino, bem como os aposentados, apresentam maior chance de uso dos serviços em comparação àquelas inseridas no mercado de trabalho, desempregadas ou estudantes.

Os resultados do estudo revelaram que para a população estudada, a equipe de saúde busca resolver as necessidades/problemas dos usuários na própria unidade, o que é favorável, haja vista que a $A B$ se propõe a responder por mais de $80 \%$ das necessidades de saúde de uma população e ser a porta preferencial do sistema de saúde. Contudo, o estudo revela também que, para os mesmos usuários, a equipe de saúde da UBS aborda principalmente as questões que levaram as pessoas a buscar o serviço de saúde, não sendo analisadas, dialogadas ou percebidas, as questões diversas que não necessariamente são objetos da consulta. A região Norte apresentou o percentual onde esta problemática é mais presente, mas as demais regiões também apresentaram frequências expressivas para esta variável, revelando lacunas quanto à integralidade do cuidado.

A integralidade vista como um atributo essencial para a organização do sistema e do processo de trabalho das equipes de saúde orienta-se pela capacidade de apreender ao máximo as necessidades de saúde da população a partir da escuta e do diálogo entre os sujeitos (profissionais de saúde e usuários) ${ }^{11}$. As práticas dos profissionais de saúde baseadas na queixa-conduta e no modelo médico- 
hegemônico distanciam-se do cuidado integral e tornam-se mais medicalizantes e limitadas do ponto de vista da autonomia do usuário. Para a mudança de modelo, é imprescindível a inversão das práticas e tecnologias, na produção da saúde e de cuidado ${ }^{11}$.

Assim, em busca da integralidade do cuidado, é preciso que o sistema de saúde seja orientado pela $A B$ e articulado em rede, mas também que seja centrado nos usuários e que respondam as suas necessidades, contemplando aspectos biológicos, psicológicos e sociais, incidindo sobre problemas coletivos nos diversos níveis de determinação dos processos saúde-enfermidade, promovendo a saúde ${ }^{12}$. Os resultados do estudo também revelam que, segundo os entrevistados, os profissionais da equipe de saúde nem sempre sugerem soluções adequadas às realidades da população, sobretudo na região Norte do país. Este mesmo achado foi percebido no estudo de Yoshida et al $^{13}$, ao referir que muitas orientações recebidas pelos usuários não são compatíveis com a realidade dos mesmos, comprometendo, assim, a resolutividade do cuidado.

Há ainda, pelo modelo médico-hegemônico, uma tendência de que o funcionamento das UBS seja centrado na consulta médica individual, rápida e com foco nas queixas e no tratamento. Desse modo, o contexto em que o usuário está inserido é colocado à margem do cuidado e as ações de promoção e de educação em saúde são geralmente de caráter autoritário e doutrinadoras ${ }^{14}$.

Outro dado revelado relaciona-se ao atendimento ser realizado sempre pelo mesmo profissional médico e/ou enfermeiro, sendo a região Norte a mais expressiva, onde os usuários referiram que não consultam com o mesmo profissional médico, e a região Sul, onde essa resposta de não continuidade foi mais frequente com relação aos profissionais enfermeiros. Além desse dado, um número importante de usuários afirmou que os profissionais de saúde não se recordam do que ocorreu nas últimas consultas. Esses dados destacam-se por estarem diretamente associados ao vínculo, à continuidade e à longitudinalidade do cuidado.

A longitudinalidade pressupõe a relação de vínculo entre os profissionais e usuários, a sequência da clínica terapêutica e os contratos de cuidado estabelecidos, além da corresponsabilização entre os sujeitos, acompanhando a 
evolução, produzindo ajustes e avaliando as condutas, sempre que se fizer necessário, evitando a perda de referências e minimizando os riscos de iatrogenia decorrentes do desconhecimento das histórias de vida e da coordenação do cuidado $^{15}$. A grande rotatividade entre os profissionais de saúde, principalmente dos profissionais médicos e enfermeiros, ocasionada por fatores internos ${ }^{16}$ (política salarial, a política de benefícios, as oportunidades de crescimento profissional, o relacionamento humano dentro da organização, as condições físicas e ambientais de trabalho, entre outros) ou externos ${ }^{16}$ (oferta e procura de recursos humanos no mercado, a conjuntura econômica, as oportunidades de emprego no mercado de trabalho) a uma organização corroboram para a dificuldade de fixar profissionais de saúde nos municípios e, assim, compromete a continuidade do cuidado, sendo consenso em outros estudos o quanto o vínculo e a longitudinalidade do cuidado são fundamentais para a qualidade da $A B$ e para a sua legitimidade social ${ }^{15,17-19}$.

Por fim, os usuários entrevistados afirmaram ter dificuldade de conversar com os profissionais de saúde após serem encaminhados para profissionais fora da unidade de saúde. E nas regiões Norte e Nordeste, principalmente, os usuários apresentam dificuldade de acesso ao resultado dos exames que chegam à UBS.

Sendo a AB responsável por coordenar o cuidado, garantindo a continuidade da atenção, é fundamental que esta possibilite o acesso oportuno dos usuários após o seu encaminhamento a outro ponto da rede e aos resultados dos exames. Como a organização das atividades nas unidades de saúde são, muitas vezes, baseadas nas ações programáticas estabelece-se uma barreira de acesso do retorno do usuário ao profissional de saúde da UBS, o que contribui para que a sequência do plano terapêutico seja comprometida.

Assim, são diversos os desafios existentes para que a coordenação do cuidado se consolide. Dentre eles, o reconhecimento institucional da $A B$ enquanto coordenadora e ordenadora da Rede de Atenção à Saúde (RAS), a mudança na organização do processo de trabalho das equipes, a necessidade de garantia de legitimidade da sociedade e dos gestores, além da inovação das práticas, a exemplo dos prontuários eletrônicos e tecnologias de informação e comunicação, o acolhimento dos usuários e a vinculação dos mesmos à $A B$. 


\section{CONSIDERAÇÕES FINAIS}

A integralidade, a longitudinalidade e a coordenação do cuidado são ainda desafios importantes para a qualidade e resolutividade da Atenção Básica no Brasil. Romper com a prática medicalizante e centrada na doença dos profissionais de saúde, que também tem sido incorporada pelos usuários, é uma tarefa que requer mudanças estruturantes, inclusive na formação dos profissionais.

Além disso, o reconhecimento da importância do vínculo estabelecido entre os usuários e profissionais de saúde para a continuidade do plano terapêutico e da autonomia e protagonismo do usuário em seu cuidado garantem tanto a qualidade da atenção, mais próxima da realidade dos usuários, bem como contribuem para a valorização da Atenção Básica, como produtora de cuidado, perante a sociedade.

Para tanto, torna-se imprescindível que a Atenção Básica seja reconhecida de modo politico e institucional, como ponto da rede de atenção, capaz de dar respostas às necessidades e demandas da população, a exemplo dos países da Europa, como Espanha, Portugal e Reino Unido, através do seu reconhecimento enquanto lócus do cuidado e centro ordenador do sistema de saúde.

Por fim, é preciso apontar que, por se tratar de um estudo descritivo, os resultados do mesmo devem ser interpretados considerando-se os aspectos metodológicos do estudo, bem como suas limitações. Dentre as limitações podemos citar o desenho, de corte transversal, e a amostragem por conveniência. Nesse sentido, os resultados não detêm a capacidade de generalização. Todavia, pela abrangência e homogeneidade metodológica do estudo, os resultados possibilitam a percepção da avaliação do usuário da Atenção Básica do Brasil, contribuindo para a análise das politicas públicas e na formulação de ações mais próximas das necessidades de saúde da população.

\section{COLABORADORES}

DCMM Figueiredo, autora principal, realizou a busca nos bancos de dados e seleção dos manuscritos adequados, organização dos resultados e redação de todo o manuscrito. HE Shimizu foi responsável pela revisão da redação de todo trabalho e colaborou para discussão dos resultados, seleção dos trabalhos adequados e 
análise e revisão do manuscrito. WM Ramalho colaborou na elaboração dos objetivos e métodos da pesquisa, na busca e seleção dos dados e análise dos resultados, elaboração das tabelas, revisão e análise final do manuscrito. 


\section{REFERÊNCIAS}

1. Green LA, Fryer GE, Yawn BP, Lanier D, Dovey SM. The ecology of medical care revisited. New England Journal of Medicine, Waltham, Mass., US, 344(26), 2021-25, 28 jun. 2001.

2. Starfield B. Primary care: concept, evaluation and policy. New York: Oxford University Press; 1992.

3. Mendes EV. A construção social da Atenção Primária à Saúde. Brasília. Conselho Nacional de Secretários de Saúde - CONASS, 2015.

4. Macinko J, Starfield B, Shi L. The contribution of primary care systems to health outcomes within Organization for Economic Cooperation and Development (OECD) countries, 1970-1998. Health Serv. Res. 2003; 38(3):831-65.

5. Ministério da Saúde (BR), Secretaria de Atenção à Saúde, Departamento de Atenção Básica. Política Nacional de Atenção Básica. Brasília: Ministério da Saúde; 2012.

6. Ministério da Saúde (BR). Portaria n.1.654, de 19 de julho de 201. Institui, no âmbito do Sistema Único de Saúde, o Programa Nacional de Melhoria do Acesso e da Qualidade da Atenção Básica (PMAQ-AB) e o Incentivo Financeiro do PMAQ-AB, denominado Componente de Qualidade do Piso de Atenção Básica Variável - PAB Variável. Diário Oficial da República Federativa do Brasil, Brasília: 20 jul. 2011. n. 138, Seção I, p. 79.

7. Crevelim MA. Participação da comunidade na equipe de saúde da família: é possível estabelecer um projeto comum entre trabalhadores e usuários? Ciênc. Saúde Coletiva. Rio de Janeiro, v. 10, n. 2, p. 323-31, 2005.

8. Moimaz SAS, Marques JAM, Saliba O, Garbin CAS, Zina LG, Saliba NA. Satisfação e percepção do usuário do SUS sobre o serviço público de saúde. Physis Revista de Saúde Coletiva, Rio de Janeiro, v. 10, n. 4, p. 1419-40, 2010.

9. Couto MT et al. Men in primary healthcare: discussing (in)visibility based on gender perspectives. Interface - Comunic Saude Educ, 14(33): 257-270, abr./jun. 2010.

10.Travassos et al. Utilização dos serviços de saúde no Brasil: gênero, características familiares e condição social. Rev Panam Salud Publica/Pan Am J Public Health 11(5/6), 2002.

11.Pinheiro R. As práticas do cotidiano na relação oferta e demanda dos serviços de saúde: um campo de estudo e construção da integralidade. In: Pinheiro R, Mattos RA. Construção da integralidade: cotidiano, saberes e práticas em saúde. Rio de Janeiro: ABRASCO; 2001. p. 65-112. 
12. Franco TB, Magalhães Junior HB. Integralidade na assistência à saúde: a organização das linhas do cuidado. O Trabalho em Saúde: olhando e experienciando o SUS no cotidiano; HUCITEC, 2004-2a. edição; São Paulo, SP.

13. Giovanella L, Mendonça MHM, Almeida PF, Escorel S, Senna MCM, Fausto MCR, et al. Saúde da família: limites e possibilidades para uma abordagem integral de atenção primária à saúde no Brasil. Ciência \& Saúde Coletiva, 14(3):783-94, 2009.

14. Yoshida VC, Andrade MGG. O cuidado à saúde na perspectiva de trabalhadores homens portadores de doenças crônicas. Interface (Botucatu). In press. Epub Mar 01, 2016.

15.Schraiber LB, Figueiredo WS, Gomes R, Couto MT, Pinheiro TF, Machin R, et al. Necessidades de saúde e masculinidades: atenção primária no cuidado aos homens. Cad. Saúde Pública. 2010; 26(5): 961-70.

16. Moraes VD, Campos CE, Brandão AL. Estudo sobre dimensões da avaliação da Estratégia Saúde da Família pela perspectiva do usuário. Physis Revista de Saúde Coletiva, Rio de Janeiro, 24 [ 1 ]: 127-146, 2014.

17. Chiavenato I. Recursos humanos. 6aa ed. São Paulo: Atlas; 2000.

18. Campos CVA, Malik AM. Satisfação no trabalho e rotatividade dos médicos do Programa de Saúde da Família. Rev. Adm. Pub. Rio de Janeiro 42(2):347-68, Mar/abr. 2008.

19. Onocko-Campos RT, Campos GWS, Ferrer AL, Corrêa CRS, Madureira R, Gama CAP, et al. Avaliação de estratégias inovadoras na organização da Atenção Primária à Saúde. Rev. Saúde Pública 2012; 46(1):43-50.

20. Medeiros CRG, Junqueira AGW, Schwingel G, Carreno I, Jungles LAP, Saldanha OMFL. A rotatividade de enfermeiros e médicos: um impasse na implementação da Estratégia de Saúde da Família. Ciência \& Saúde Coletiva, 15 (Supl. 1):1521-31, 2010. 


\section{CONSIDERAÇÕES FINAIS}

No Brasil, são perceptíveis os avanços obtidos a partir da expansão da Atenção Básica, especialmente após a ESF, trazendo a Atenção Básica para o centro do debate enquanto dispositivo estruturante e ordenador do cuidado no SUS, bem como favorecendo a universalização dos cuidados primários e contribuindo para a implantação de processos avaliativos importantes para 0 seu aperfeiçoamento.

Todavia, este esforço por si não é suficiente no sentido da garantia do acesso e da qualidade na atenção, sendo determinante que os investimentos nas políticas institucionais permitam extrapolar a cobertura e aportem, também, a formação e valorização dos profissionais, as relações intersetoriais, a estrutura física e ambiência e as tecnologias que permitam a produção de cuidado a partir de práticas acolhedoras, criativas e resolutivas.

É possível perceber que as ações e programas voltados para a qualidade da Atenção Básica já se direcionam nesse sentido, a exemplo do Programa de Requalificação das UBS, o investimento na informatização das unidades, o Prontuário Eletrônico do Cidadão, as equipes de NASF, os Núcleos de Telessaúde e o PMAQ-AB.

Neste estudo, foi possível verificar que ainda existem muitos desafios a serem enfrentados, sendo necessário reconhecer os problemas existentes, em busca de produzir mudanças, possibilitando que a $A B$ seja capaz de cumprir seu papel estruturante no SUS.

A acessibilidade em saúde na Atenção Básica, em suas duas dimensões, ainda é considerada como grande desafio para a implementação das políticas no Brasil, sobretudo se considerarmos as diversidades regionais. Além das barreiras geográficas, é imprescindível romper com as barreiras de organização e funcionamento dos serviços, valorizando as clínicas dos diversos profissionais de saúde e da abordagem centrada nos usuários e não na doença, incorporando no cotidiano das equipes a gestão da clínica, baseada no cuidado compartilhado e da clínica ampliada do cuidado, e do saber do usuário, enquanto responsável pelo seu projeto terapêutico. 
Além disso, é necessário compreender as diversas necessidades que permeiam os usuários e suas famílias, fortalecendo os vínculos entre profissionais de saúde e comunidade, bem como a partir de políticas, investimento e tecnologias que possibilitem à gestão, a formação dos profissionais, e à rotina dos profissionais e usuários estratégias de reconhecimento da $A B$ como coordenadora do cuidado na rede de atenção à saúde. 


\section{REFERÊNCIAS}

ADAY L.A.; ANDERSEN R. A framework for the study of access to medical care. Health Serv. Res.v.9 n. 3, 1974.

ALMEIDA, P.F. et al. Estratégias de integração entre atenção primária à saúde e atenção especializada: paralelos entre Brasil e Espanha. Saúde em Debate. Rio de Janeiro, v. 37, n. 98, p. 400-415, jul/set 2013.

ANDERSEN, R.A.; NEWMAN, J.F. Societal and individual determinants of medical care utilization in the United States. Milbank Mem Fund Q Health Soc. v. 83 n. 4. 2005.

AQUINO, R.; OLIVEIRA, N.F. de; BARRETO, M.L. Impact of the Family Health Program on Infant Mortality in Brazilian Municipalities. American Journal of Public Health, Boston, v. 99, n. 1, p. 87-93, jan. 2009.

BEZERRA FILHO, J. G. et al. Spatial distribution of the infant mortality rate and its principal determinants in the State of Ceará, Brazil, 2000-2002. Cadernos de Saúde Pública, Rio de Janeiro, v. 3, n. 5, p. 1173-1185, maio 2007.

BRASIL. Ministério da Saúde. Decreto 7.508, de 28 de junho de 2011. Regulamenta a Lei no 8.080, de 19 de setembro de 1990, para dispor sobre a organização do Sistema Único de Saúde-SUS, o planejamento da saúde, a assistência à saúde e a articulação interfederativa, e dá outras providências. Diário Oficial da União, no 123, seção 1, p. 1-4. Brasília, 29 de junho de 2011 a.

. Ministério da Saúde. Portaria no 1.654, de 19 de julho de 2011. Institui, no âmbito do Sistema Único de Saúde, o Programa Nacional de Melhoria do Acesso e da Qualidade da Atenção Básica (PMAQ-AB) e o Incentivo Financeiro do PMAQ-AB, denominado Componente de Qualidade do Piso de Atenção Básica Variável - PAB Variável. Diário Oficial da União, ㄲo 138, seção 1, p. 79-80. Brasília, 20 de julho de $2011 b$.

. Ministério da Saúde. Portaria o 2.812, de 29 de novembro de 2011. Homologa a adesão dos Municípios e das respectivas equipes de Atenção Básica ao Programa Nacional de Melhoria do Acesso e da Qualidade da Atenção Básica (PMAQ-AB). Diário Oficial da União, № 229, seção 1, p. 38-57. Brasília, 30 de novembro de 2011c.

. Ministério da Saúde. Secretaria de Atenção à Saúde. Departamento de Atenção Básica. Programa Nacional de Melhoria do Acesso e da Qualidade da Atenção Básica (PMAQ-AB): Manual Instrutivo. Brasília: Ministério da Saúde, 2011d.

Ministério da Saúde. Secretaria de Atenção à Saúde. Departamento de Atenção Básica. Política Nacional de Atenção Básica. Ministério da Saúde. Secretaria de Atenção à Saúde. Departamento de Atenção Básica. Brasília: Ministério da Saúde, 2012a. 
. Ministério da Saúde. Portaria no 225, de 10 de fevereiro de 2012. Homologa a adesão dos Municípios e das respectivas equipes de Atenção Básica ao Programa Nacional de Melhoria do Acesso e da Qualidade da Atenção Básica (PMAQ-AB). Diário Oficial da União. Brasília, 11 de fevereiro de 2012b.

. Ministério da Saúde. Portaria no 644, de 10 de abril de 2012. Homologa a adesão dos Municípios e das respectivas equipes de Atenção Básica ao Programa Nacional de Melhoria do Acesso e da Qualidade da Atenção Básica (PMAQ-AB). Diário Oficial da União, nº 70, seção 1, p.120. Brasília, 11 de abril de 2012c.

- Ministério da Saúde. Secretaria de Atenção à Saúde. Departamento de Atenção Básica. Saúde Mais Perto de Você - Acesso e Qualidade: Programa Nacional de Melhoria do Acesso e da Qualidade da Atenção Básica (PMAQAB): Documento Síntese para a Avaliação Externa. / Ministério da Saúde. Secretaria de Atenção à Saúde. Departamento de Atenção Básica. Brasília: Ministério da Saúde, 2012d.

- Ministério da Saúde. Secretaria de Atenção à Saúde. Departamento de Atenção Básica. Instrumento de Avaliação Externa do Programa Saúde Mais Perto de Você - Acesso e Qualidade: Programa Nacional de Melhoria do Acesso e da Qualidade da Atenção Básica (PMAQ) / Ministério da Saúde. Secretaria de Atenção à Saúde. Departamento de Atenção Básica. Brasília: Ministério da Saúde, 2012 e.

- Ministério do Planejamento, Orçamento e Gestão. Instituto Brasileiro de Geografia e Estatística. Diretoria de Pesquisas. Coordenação de Trabalho e Rendimento. Pesquisa Nacional de Saúde 2013: Acesso e utilização dos serviços de saúde, acidentes e violência. Rio de Janeiro, 2014.

CONILL, E.M. Ensaio histórico-conceitual sobre a Atenção Primária à Saúde: desafios para a organização de serviços básicos e da estratégia saúde da família em centros urbanos no Brasil. Cadernos de Saúde Pública, Rio de Janeiro, v. 24, supl. 1, p. 7-16, 2008.

CREVELIM, M.A. Participação da comunidade na equipe de saúde da família: é possível estabelecer um projeto comum entre trabalhadores e usuários? Ciênc. Saúde Coletiva. Rio de Janeiro, v. 10, n. 2, p. 323-331, 2005.

DONABEDIAN, A. Aspects of medical care administration. Boston: Harvard University Press; 1973.

DONABEDIAN, A. The Definition of Quality and Approaches to its Assessment. Michigan: Health Administration Press, 1980.

ESCOREL, S. et al. O Programa de Saúde da Família e a construção de um novo modelo para a atenção básica no Brasil. Rev. Panam Salud Publica/Pan Am J Public Health v. 21(2), 2007.

FACCHINI, L.A. et al. Performance of the PSF in the Brazilian South and Northeast: institutional and epidemiological assessment of Primary Health Care. Ciência \& Saúde Coletiva, Rio de Janeiro, v. 11, n. 3, p. 669-681, set. 2006. 
FACCHINI, L. A. et al. Avaliação de efetividade da Atenção Básica à Saúde em municípios das regiões Sul e Nordeste do Brasil: contribuições metodológicas. Cadernos de Saúde Pública, Rio de Janeiro, v. 24, p. s159-s172, jan. 2008.

GIOVANELLA, L. A atenção primária à saúde nos países da União Européia: configurações e reformas organizacionais na década de 1990. Cad. Saúde Pública, Rio de Janeiro, v.22, n. 5 p.951-963, mai, 2006.

GOUVEIA, G. C. et al. Health care user satisfaction in Brazil, 2003. Cad. Saúde Pública, Rio de Janeiro, v.21 supl. S109-S118, 2005.

GREEN, L. A. et al. The ecology of medical care revisited. New England jornal of medicine, Waltham, Mass., US, v. 344, n. 26, p. 2021-2025, 28 jun. 2001.

HARTZ, Z. M. A.; CONTANDRIOPOULOS, A. P. Integralidade da atenção e integração de serviços de saúde: desafios para avaliar a implantação de um "sistema sem muros". Cad. Saúde Pública. v.20, supl.2 Rio de Janeiro. 2004.

MACINKO, J.; STARFIELD, B.; SHI, L. The contribution of primary care systems to health outcomes within Organization for Economic Cooperation and Development (OECD) countries, 1970-1998. Health services research, Ann Arbor, Mich., US, v. 38, n. 3, p. 831-865, jun. 2003.

MACINKO, J. et al. Evaluation of the impact of the Family Health Program on infant mortality in Brazil, 1990-2002. Journal of epidemiology and community health, London, v. 60, n. 1, p. 13-19, jan. 2006.

MACINKO, J. et al. Going to scale with community-based primary care: an analysis of the family health program and infant mortality in Brazil, 1999-2004. Social science \& medicine (1982), Oxford, v. 65, n. 10, p. 2070-2080, nov. 2007.

MACINKO, J; LIMA COSTA, M. F. Access to, use of and satisfaction with health services among adults enrolled in Brazil's Family Health Strategy: evidence from the 2008 National Household Survey. Trop Med Int Health, v.17, n. 36, 2012.

MACINKO, J; HARRIS, M. J. Brazil's family health strategy-delivering communitybased primary care in a universal health system. New England Journal of Medicine, v.372, n. 23, p. 2177-2181, 2015.

MOIMAZ, S.A.S. et al. Satisfação e percepção do usuário do SUS sobre o serviço público de saúde. Physis Revista de Saúde Coletiva, Rio de Janeiro, v. 10, n. 4, p. 1419-1440, 2010.

ORGANIZAÇÃO MUNDIAL DE SAÚDE (OMS). Conferência Internacional sobre Cuidados Primários de Saúde. Alma-Ata, URSS, 6-12 de setembro de 1978.

PAIM, J. et al. O sistema de saúde brasileiro: história, avanços e desafios. The Lancet, London, p.11-31, maio. 2011. Disponível em: <http://download.thelancetcom/flatcontentassets/pdfs/brazil/brazilpor1.pdf >. Acesso em: 15 de dezembro de 2015. 
PENCHANSKY, R.; THOMAS, W.J. The concept of access: definition and relationship to consumer satisfaction. Med Care. v.19, n.2, 1981.

PINTO, H.A.; SOUSA, A.N.; FERLA, A.A. O Programa Nacional de Melhoria do Acesso e da Qualidade da Atenção Básica: várias faces de uma política inovadora. Rev. Divulgação em Saúde para debate. Rio de Janeiro, n. 51, p. 43-57, out. 2014.

REIS, A.T.; OLIVEIRA, P.T.R.; SELLERA, P.E. Sistema de Avaliação para a Qualificação do Sistema Único de Saúde (SUS). RECIIS - R. Eletr. de Com. Inf. Inov. Saúde, 6 (Supl.2), 2012.

SERAPIONI, M. Avaliação da Qualidade em Saúde. Saúde em Debate, Rio de Janeiro, v. 23, n. 53, p. 81-92, set/dez. 1999.

STARFIELD, B. Atenção Primária: equilíbrio entre necessidades de saúde, serviços e tecnologia. Brasília: Organização das Nações Unidas para a Educação, a Ciência e a Cultura/Ministério da Saúde, 2002.

SOUSA, M.F. Programa Saúde da Família no Brasil: Análise da desigualdade no acesso à atenção básica. Brasília: Ed. do Departamento de Ciência da Informação e Documentação da Universidade de Brasília, 2007. 250 p.

TANAKA, O.Y.; RIBEIRO, E.L. Ações de saúde mental na atenção básica: caminho para ampliação da integralidade da atenção. Ciênc. Saúde Coletiva, v.14, n.2, abr. 2009, p.477- 486. 
ANEXOS

\section{ANEXO A - COMPROVANTE DE SUBMISSÃO DO ARTIGO À REVISTA CADERNOS DE SAÚDE PÚBLICA}

Novo artigo (CSP_0570/16)

Cadernos de Saude Publica 〈cadernos@fiocruz.br>

Abr 7 em 1:57 PM

Para dla.moreira@yahoo.com.br

Prezado(a) Dr(a). DANIELA CRISTINA M. M. DE FIGUEIREDO:

Confirmamos a submissão do seu artigo "As dimensões da acessibilidade em saúde: como avaliam os usuários da Atenção Básica?" (CSP_.0570/16) para Cadernos de Saúde Pública. Agora será possivel acompanhar o progresso de seu manuscrito dentro do processo editorial, bastando clicar no link "Sistema de Avaliação e Gerenciamento de Artigos", localizado em nossa página http://www.ensp.fiocruz.br/csp.

Em caso de dúvidas, envie suas questôes através do nosso sistema, utilizando sempre o ID do manuscrito informado acima. Agradecemos por considerar nossa revista para a submissão de seu trabalho,

Atenciosamente,

Profà. Marilia Sá Carvalho

Profa. Claudia Medina Coeli

Profa, Luciana Dias de Lima

Editoras

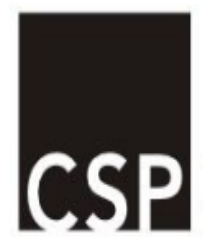

Cadernos de Saúde Pública / Reports in Public Health

Escola Nacional de Saúde Pública Sergio Arouca

Fundaçăo Oswaldo Cruz

Rua Leopoldo Bulhōes 1480

Rio de Janeiro, RJ 21041-210, Brasil

Tel.: +55 (21) 2598-2511, 2508 / Fax: +55 (21) 2598-2737

cadernos@ensp.fiocruz.br

http://www.ensp. fiocruz.br/csp

$\leftarrow \Rightarrow$ C [ cadernos.ensp.fiocruz.br/csp/index.php?whattodo=autor_artigo_exibir\&id=20333

Login: danimoreira Português English Español

\section{SAGAS}

Sistema de Avaliação e Gerenciamento de Artigos

Cadernos de Saúde Pública / Reports in Public Health

Inicio Autor Consultor Editor Mensagens Sair

\section{CSP_0570/16}

\begin{tabular}{|l|l|}
\hline Arquivos & Versão $1 \quad$ [Resumo] \\
\hline Seção & Artigo \\
\hline Título & As dimensões da acessibilidade em saúde: como avaliam os usuários da Atenç̧ão Básica? \\
\hline Título corrido & Avaliação das dimensões da Acessibilidade na Atenção Básica \\
\hline Área de Concentração & Politicas Públicas de Saúde \\
\hline Palavras-chave & Acesso aos Serviços de Saúde, Atenção Primária à Saúde, Avaliação em saúde \\
\hline Autores & $\begin{array}{l}\text { Daniela Cristina Moreira Marculino de Figueiredo (Universiddade de Braślila (UnB)) } \\
\text { Helena Eri Shimizu (Universidade de Brasilia) } \\
\text { Walter Massa Ramalho (Universidade de Brasilia) }\end{array}$ \\
\hline
\end{tabular}

DECISŐES EDITORIAIS: [Exibir histórico]

\begin{tabular}{|c|c|c|c|c|}
\hline Versão & Recomendação & Decisäo & Pareceres & Data de Submissäo \\
\hline 1 & \multicolumn{3}{|c|}{ Em avaliação. Artigo enviado em 07 de Abril de 2016. } \\
\hline
\end{tabular}




\section{ANEXO B - COMPROVANTE DE SUBMISSÃO DO ARTIGO À REVISTA CIÊNCIA E SAÚDE COLETIVA.}

Artigo submetido à chamada pública para número temático: A Política pública de Atenção Primária no Brasil - Dilemas, rupturas e desafios.

E-mail de envio: publicação.dcs@gmail.com 


\section{APÊNDICE}

\section{APÊNDICE A - VARIÁVEIS DO BANCO DE DADOS}

\section{CARACTERIZAÇÃO DA AMOSTRA}

III_4_6 Sexo

III_4_7 Qual a idade do (a) senhor (a)?

III_4_8 Dentre as opções que vou ler, qual a sua cor ou raça?

III_4_15 A sua família possui renda mensal?

III_4_15/1 Qual o valor?

III_4_16 A sua família é cadastrada no Programa Bolsa Família?

III_4_17 A sua família recebe o dinheiro do Programa Bolsa Família atualmente?

\section{DIMENSÕES DA ACESSIBILIDADE EM SAÚDE}

III5_2 O que o senhor (a) acha da distância da sua casa até esta Unidade de Saúde?

III_5_4 A Unidade de Saúde funciona cinco dias na semana?

III_5_7 O horário de funcionamento desta unidade atende às suas necessidades?

III_5_8 Para facilitar o seu atendimento o(a) senhor (a) gostaria que a unidade de saúde atendesse:

III_5_8_1 Mais cedo pela manhã

III_5_8_2 À tarde até as $18 \mathrm{~h}$

III_5_8_3 À noite

III_5_8_4 Aos sábados

III_5_8_5 No horário do almoço

III_5_8_6 Outros

III5_9 O médico está presente na unidade de saúde ou em atividades no bairro durante todos os horários de funcionamento da Unidade de Saúde?

III5_10 Se o (a) senhor (a) quiser, pode escolher a equipe que the atende? (médico, enfermeiro, ACS ou outros) 
III6_1 Na maioria das vezes, como o (a) senhor (a) faz para marcar consulta na unidade de saúde?

III_7_7 Na última vez que o (a) senhor (a) teve algum problema de saúde que considerou uma urgência, o (a) senhor (a) procurou atendimento?

III_7_8_1 O senhor procurou atendimento nesta unidade de saúde quando apresentou problema que considerou urgência?

III_7_12 Por que não procurou esta unidade de saúde para este atendimento (urgência)?

INTEGRALIDADE, LONGITUDINALIDADE E COORDENAÇÃO DO CUIDADO

III_8_1 A equipe de saúde busca resolver as suas necessidades/problemas, na própria unidade de saúde?

III_8_7 Os profissionais de saúde fazem sempre perguntas sobre outras necessidades de saúde além daquelas relacionadas com o motivo da consulta?

III_8_8 Os profissionais da equipe de saúde da AB sempre sugerem soluções adequadas às suas realidades?

III_9_7 Nessa unidade o (a) senhor (a) é atendido pelo mesmo médico?

III_9_9 Nessa unidade o (a) senhor (a) é atendido pelo mesmo enfermeiro?

III_9_13 Os profissionais lembram-se do que aconteceu nas últimas consultas do (a) senhor (a)?

III_9_21 Depois que o (a) senhor (a) foi atendido (a) por outros profissionais fora desta unidade de saúde, a equipe conversou com o (a) senhor (a) sobre este atendimento?

III_9_22 O (a) senhor (a) encontra facilidade para saber dos resultados dos seus exames que chegam nesta unidade de saúde? 